\title{
Synaptic Activity Induces Dramatic Changes in the Geometry of the Cell Nucleus: Interplay between Nuclear Structure, Histone H3 Phosphorylation, and Nuclear Calcium Signaling
}

\author{
Malte Wittmann, ${ }^{1 \star}$ Gillian Queisser, ${ }^{2,3 *}$ Anja Eder, ${ }^{1 *}$ J. Simon Wiegert, ${ }^{1 \star}$ C. Peter Bengtson, ${ }^{1 \star}$ Andrea Hellwig, ${ }^{1 *}$ \\ Gabriel Wittum, ${ }^{2,3}$ and Hilmar Bading ${ }^{1,3}$ \\ ${ }^{1}$ Department of Neurobiology, Interdisciplinary Center for Neurosciences (IZN), ${ }^{2}$ Simulation in Technology, Interdisciplinary Center for Scientific \\ Computing (IWR), and ${ }^{3}$ Excellence Cluster CellNetworks at University of Heidelberg, 69120 Heidelberg, Germany
}

\begin{abstract}
Synaptic activity initiates many adaptive responses in neurons. Here we report a novel form of structural plasticity in dissociated hippocampal cultures and slice preparations. Using a recently developed algorithm for three-dimensional image reconstruction and quantitative measurements of cell organelles, we found that many nuclei from hippocampal neurons are highly infolded and form unequally sized nuclear compartments. Nuclear infoldings are dynamic structures, which can radically transform the geometry of the nucleus in response to neuronal activity. Action potential bursting causing synaptic NMDA receptor activation dramatically increases the number of infolded nuclei via a process that requires the ERK-MAP kinase pathway and new protein synthesis. In contrast, deathsignaling pathways triggered by extrasynaptic NMDA receptors cause a rapid loss of nuclear infoldings. Compared with near-spherical nuclei, infolded nuclei have a larger surface and increased nuclear pore complex immunoreactivity. Nuclear calcium signals evoked by cytosolic calcium transients are larger in small nuclear compartments than in the large compartments of the same nucleus; moreover, small compartments are more efficient in temporally resolving calcium signals induced by trains of action potentials in the theta frequency range $(5 \mathrm{~Hz})$. Synaptic activity-induced phosphorylation of histone $\mathrm{H} 3$ on serine 10 was more robust in neurons with infolded nuclei compared with neurons with near-spherical nuclei, suggesting a functional link between nuclear geometry and transcriptional regulation. The translation of synaptic activity-induced signaling events into changes in nuclear geometry facilitates the relay of calcium signals to the nucleus, may lead to the formation of nuclear signaling microdomains, and could enhance signal-regulated transcription.
\end{abstract}

\section{Introduction}

Cells undergo functional and morphological alterations following stimulation from their environment. Among the best-characterized signal-regulated intracellular biochemical consequences are changes in gene expression. In neurons, transcriptional responses, triggered by electrical activity and mediated by NMDA receptor-induced calcium signaling pathways, are essential for most long-lasting adaptive responses and, in particular, play a key role in information storage and memory formation (Milner et al., 1998; Bading, 2000; West et al., 2002). However, there is an increasing appreci-

\footnotetext{
Received March 10, 2009; revised Sept. 16, 2009; accepted Sept. 21, 2009.

This work was supported by the Alexander von Humboldt Foundation (Wolfgang Paul Prize to H.B.), the Deutsche Forschungsgemeinschaft, SFB 488, SFB 636, the European Union (EU) Network of Excellence NeuroNE, the EU Project GRIPANNT, and the Bundesministerium fuer Bildung und Forschung (Project DMSPiN). M.W. was supported by the Boehringer Ingelheim Fonds. We thank Harald Hermann-Lerdon for the antibodies to lamin $B$ and lamin $A / C$, Jan Ellenberg for the lamin B-GFP construct, Alexei Ponomarenko for his help with power spectrum analysis, Ursula Weiss for carrying out immunoblot analyses, and Dirk Görlich for discussion.

*M.W., G.Q., A.E., J.S.W., C.P.B., and A.H. contributed equally to this study.

Correspondence should be addressed to Hilmar Bading, Department of Neurobiology, Interdisciplinary Center for Neurosciences, University of Heidelberg, Im Neuenheimer Feld 364, 69120 Heidelberg, Germany. E-mail: Hilmar.Bading@uni-hd.de.

G. Wittum's present address: Goethe-Zentrum für Wissenschaftliches Rechnen (G-CSC), Goethe-Universität, Kettenhofweg 139, 60325 Frankfurt am Main, Germany.

J. S. Wiegert's present address: Friedrich Miescher Institute, Maulbeerstrasse 66, CH-4058 Basel, Switzerland. DOl:10.1523/JNEUROSCI.1160-09.2009

Copyright $\odot 2009$ Society for Neuroscience $\quad$ 0270-6474/09/2914687-14\$15.00/0
}

ation of the importance of cell shape changes in modulating function. For example, the dendritic trees of neurons can undergo activity-induced geometry changes that will alter the neurons' ability to receive, process, and transmit information within the network (Muller et al., 2002; Van Aelst and Cline, 2004; Hayashi and Majewska, 2005; Tada and Sheng, 2006). Moreover, a computational analysis suggests that changes in the overall size or shape of a cell allows gradient-controlled signaling pathways to be switched on or off by changing the distance between the source of the signal and its targets (Meyers et al., 2006). In this study, we investigated the possibility that not only the cell surface geometry but also the geometry of cell organelles can undergo signalinduced, functionally relevant alterations. We focused on the nucleus because we reasoned that nuclear geometry changes may have an impact on the amplitude and/or kinetics of nuclear calcium signals following cytosolic calcium transients and thus could modulate the way calcium relays information to the nucleus. We used a recently developed algorithm to reconstruct the three-dimensional (3D) structure of neuronal nuclei from confocal microscopy data and quantified their volumes and surface areas. We found that nuclei from hippocampal neurons are extremely plastic and can adopt either near-spherical or complex, highly infolded structures, which affects the propagation of calcium signals into the nucleus and the activation of transcriptionregulating events. NMDA receptor signaling pathways and the 
ERK-MAP kinases regulate the geometry of the nucleus, with synaptic and extrasynaptic NMDA receptors having opposing effects.

\section{Materials and Methods}

Hippocampal cultures and stimulations. Hippocampal neurons from Sprague Dawley rats were cultured as described (Bading and Greenberg, 1991), except that growth medium was supplemented with B27 (Invitrogen). Cultures were plated onto $12 \mathrm{~mm}$ glass coverslips at a density of $\sim 450$ cells (neurons plus glial cells) per $\mathrm{mm}^{2}$. Stimulations were done after a culturing period of 9-10 d during which hippocampal neurons develop a rich network of processes, express functional NMDA-type and AMPA/kainate-type glutamate receptors, and form synaptic contacts (Bading et al., 1995; Arnold et al., 2005). NMDA, D(-)-APV, MK-801, anisomycin and cycloheximide were from Sigma; bicuculline was from MP Biomedicals; actinomycin D was from AppliChem; tetrodotoxin (TTX) was from Tocris Bioscience; PD98059 and 4-aminopyridine were from Calbiochem (Merck); UO126 was from Axxora; DiD was from Biotrend Chemikalien. All experiments in which signal-regulation of nuclear geometry was analyzed were done at $37^{\circ} \mathrm{C}$. DNA transfection was done using Lipofectamine 2000 (Invitrogen).

Organotypic hippocampal slice cultures. Brain slices were prepared from 6-d-old Sprague Dawley rats. The pups were decapitated and the brains were removed and placed for trimming the tissue into a block into icecold dissection medium [Hanks' basal salt solution (Invitrogen) supplemented with glucose (Sigma) at a final concentration of $6.5 \mathrm{mg} / \mathrm{ml}$. Brains were then transferred to the Teflon stage of a tissue chopper $(\mathrm{H}$. Saur Laborbedarf, Reutlingen, Germany) and 350- $\mu$ m-thick slices were cut. Hippocampal slices were micro-dissected from each brain slice in ice-cold dissection medium and transferred onto PTFE-cell culture inserts (Millipore). The slices were kept in a humidified atmosphere (5\% $\mathrm{CO}_{2} / 95 \%$ air) at $37^{\circ} \mathrm{C}$ for 2 weeks as described (Stoppini et al., 1991), except that the culturing medium had the following composition: $50 \mathrm{ml}$ of Basal Medium Eagle, $25 \mathrm{ml}$ of Earle's balanced salt solution with $\mathrm{Ca}^{2+}$, $\mathrm{Mg}^{2+}$, Phenol Red (Sigma), $25 \mathrm{ml}$ of horse serum (Invitrogen), 6.5 $\mathrm{mg} / \mathrm{ml}$ glucose, $1 \mathrm{~mm} \mathrm{~L}$-glutamine and $0.5 \%$ penicillin/streptomycin (Sigma). Half of the medium was replaced every $3 \mathrm{~d}$.

Immunocytochemistry. Cultured hippocampal neurons were fixed between day in vitro (DIV) 10 and 14 with PBS containing 2\% (w/v) paraformaldehyde and $2 \%(\mathrm{w} / \mathrm{v})$ sucrose for $10 \mathrm{~min}$ at room temperature. Cells were washed 2 times with PBS, followed by incubation with the primary antibodies in PBS containing $0.1 \%(\mathrm{v} / \mathrm{v})$ Triton X-100 and $2 \%$ $(\mathrm{w} / \mathrm{v})$ bovine serum albumin (BSA). Antibodies to the following proteins were used: lamin B and lamin A/C (mouse monoclonal antibodies, generous gift from Harald Hermann-Lerdon, German Cancer Research Center, Heidelberg, Germany; the monoclonal antibody to lamin B binds to rat lamin B1 and rat lamin B2); nuclear pore complex proteins recognized by Mab414 (mouse monoclonal antibody; Abcam), the nuclear pore complex protein NUP93 (mouse monoclonal antibody; Abcam), histone $\mathrm{H} 3$ phosphorylated at serine 10 (rabbit polyclonal antibody; Millipore), MSK1 phosphorylated at threonine 581 (rabbit polyclonal antibody; Cell Signaling Technology). The following antibody dilutions were used: anti-lamin B and anti-lamin A/C cell culture supernatant: 1:10; Mab414: 1:5000; NUP93: 1:2000; anti-phospho-histone H3: 1:200; anti phospho-MSK1: 1:200. All incubations with primary antibodies were done for $1 \mathrm{~h}$ at room temperature. Cells were washed 3 times with PBS and incubated for $15 \mathrm{~min}$ at room temperature with PBS containing $0.1 \%$ (v/v) Triton X-100, 2\% (w/v) BSA and either Alexa 488-labeled secondary antibodies (Invitrogen) or Cy3-labeled secondary antibodies (Jackson ImmunoResearch). For nuclear counterstaining Hoechst 33258 (Serva) was applied in a 1:5000 dilution for 5 min. Cells were washed with PBS and were mounted using a Mowiol-based mounting medium. Experiments in which the cultured neurons were fixed with methanol for 10 min at $-20^{\circ} \mathrm{C}$ generated virtually identical results. Specimens were analyzed using a Leica SP2 confocal microscope (Leica). Different regions of the coverslips were imaged using identical microscope settings and the same number of planes within the projection. To quantify nuclear pore complex (NPC) immunoreactivity, stacks of confocal images spanning the entire nucleus were projected by summation onto a single plane using $\mathrm{NIH}$ ImageJ. Regions of interest were defined for near-spherical and infolded nuclei and the mean fluorescence was measured. Mean values of both groups of nuclei were averaged and the percentage differences were plotted as arbitrary values.

For brain section immunohistochemistry, Sprague Dawley rats were killed by transcardiac perfusion under deep anesthesia (pentobarbital). After perfusion with PBS, brains were fixed by perfusion with $4 \%(\mathrm{w} / \mathrm{v})$ paraformaldehyde in PBS. Brains were removed and postfixed overnight in the same fixative before cryoprotection in $30 \%(\mathrm{w} / \mathrm{v})$ sucrose in PBS. Coronal sections $(40 \mu \mathrm{m})$ were cut using a cryostat. Free-floating sections were rinsed with PBS and permeabilized with PBS containing $0.2 \%$ $(\mathrm{v} / \mathrm{v})$ Triton X-100 and 5\% (w/v) BSA for $2 \mathrm{~h}$. Sections were rinsed with PBS and incubated overnight with the monoclonal antibody to lamin B or with Mab414 at room temperature in PBS containing 5\% (w/v) BSA and $0.2 \%(\mathrm{v} / \mathrm{v})$ Triton X-100. Sections were washed with PBS before incubation with Alexa 488-labeled secondary antibodies (dilution $1: 1000)$ for $2 \mathrm{~h}$ at room temperature, followed by extensive washing with PBS. Specimens were analyzed using a Leica SP2 confocal microscope.

For immunohistochemistry using organotypic slice cultures, the membranes holding the slices were briefly dipped into $37^{\circ} \mathrm{C}$ warm PBS to wash away any remaining growth medium before they were fixed with $2 \%$ paraformaldehyde $(\mathrm{w} / \mathrm{v}) / 2 \%$ sucrose $(\mathrm{w} / \mathrm{v})$ in PBS for $4 \mathrm{~h}$ at room temperature. Slices were subsequently washed with PBS and permeabilized in $0.1 \%$ Triton X-100 in PBS-Tween $(0.1 \%)$ (PBS-T) overnight. Any remaining free aldehyde groups were then quenched with $50 \mathrm{~mm}$ glycine for $1 \mathrm{~h}$ at room temperature. After washing with PBS-T, slices were blocked with $10 \%$ normal goat serum, 2\% BSA in PBS-T for $4 \mathrm{~h}$ at room temperature before they were incubated with the primary antibodies in $2 \%$ normal goat serum, $2 \% \mathrm{BSA}$ in PBS-T overnight at $4^{\circ} \mathrm{C}$. The primary antibodies (mouse monoclonal antibody to lamin $\mathrm{A} / \mathrm{C}$ and rabbit polyclonal antibody to histone $\mathrm{H} 3$ phosphorylated at serine 10) and secondary antibodies used and their dilutions were identical to the ones used for immunocytochemistry of dissociated hippocampal cultures (see above). For nuclear counterstaining, Hoechst 33258 (Serva) was applied in a 1:5000 dilution for $5 \mathrm{~min}$. Slices were washed with PBS and mounted in a Mowiol-based mounting medium. See supplemental material, available at www.jneurosci.org, for details on transmission electron microscopy.

$3 D$ image reconstruction and mathematical modeling. The mathematical framework for the 3D image reconstruction of cell nuclei has been described (Queisser et al., 2008). See supplemental material, available at www.jneurosci.org, for a brief description of the algorithms used and for details of the mathematical modeling of nuclear calcium dynamics in nuclei with different geometries.

Confocal microscopy and calcium imaging. For calcium imaging cells were loaded with Fluo-4 AM (3.6 $\mu \mathrm{M})$ (Invitrogen) and nuclear compartments were visualized by concurrent loading with ER-Tracker BlueWhite DPX dye $(1 \mu \mathrm{M})$ (Invitrogen). Fluorescence images were obtained using an inverted Leica SP2 confocal microscope with an HCX PL APO CS $40.0 \times 1.25$ NA OIL UV objective. Cells were mounted in a perfusion chamber (LIS) and imaged at room temperature in a $\mathrm{CO}_{2}$-independent buffered salt-glucose-glycine (SGG) solution containing (in $\mathrm{mM}$ ) $\mathrm{NaCl}$ 140.1, $\mathrm{KCl} 5.3, \mathrm{MgCl}_{2}$ 1.0, $\mathrm{CaCl}_{2}$ 2.0, HEPES 10.0, glycine 1.0, glucose 30.0 , and sodium pyruvate 0.5 . The image acquisition rate was $1.5 \mathrm{~Hz}$. To calibrate the fluorescence signal $(F)$, Fluo- 4 was saturated by adding 50 $\mu \mathrm{M}$ ionomycin (MP Biomedicals) to the perfusion solution to obtain the maximal fluorescence signal $\left(F_{\max }\right)$ and then quenched with $\mathrm{MnCl}_{2}$ to obtain the minimal fluorescence signal $\left(F_{\text {min }}\right)$. $\left[\mathrm{Ca}^{2+}\right]$ was expressed as a function of the Fluo-4 fluorescence $K_{\mathrm{d}} \times\left[\left(F-F_{\min }\right) /\left(F_{\max }-F\right)\right]$ (Grynkiewicz et al., 1985). The validity of calcium measurements critically depends on the accuracy of the calibration, particularly when calcium concentrations are being analyzed and compared in different cellular compartments. To avoid artifacts, calibration was done pixel by pixel to relate the fluorescence values to the corresponding values obtained during the calibration. See supplemental material, available at www.jneurosci.org, for details on combined patch-clamp and calcium imaging using X-Rhod-1 and fura-2, and for details on calcium imaging using organotypic hippocampal slice cultures. 
A
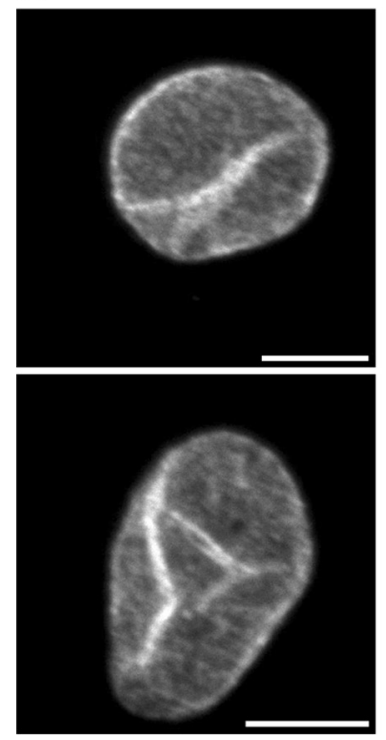

B
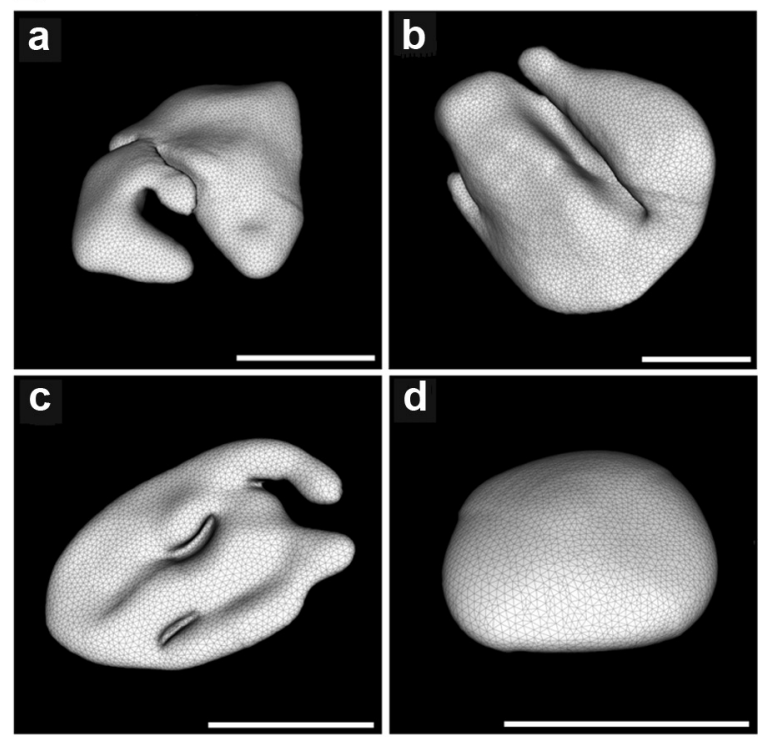

Figure 1. Images of nuclei from hippocampal neurons. $\boldsymbol{A}$, Projections from confocal stacks of nuclei from cultured hippocampal neurons immunostained with monoclonal antibodies to lamin B. Examples of two infolded nuclei are shown. Scale bars, $5 \mu \mathrm{m}$. $\boldsymbol{B}$, Three-dimensional image reconstructions using confocal microscopy stacks of nuclei from cultured hippocampal neurons. Examples of 3 different infolded nuclei $(\boldsymbol{a}-\boldsymbol{c})$ and 1 near-spherical nucleus $(\boldsymbol{d})$ are shown. Scale bars correspond to $5 \mu \mathrm{m}$ of the z-projections of the images.
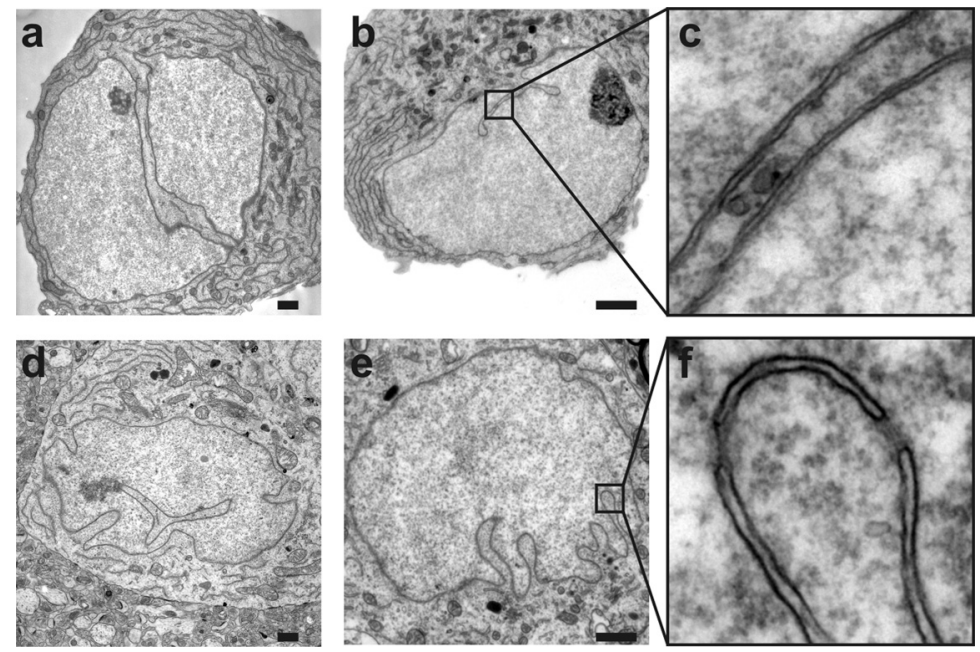

Figure 2. Electron micrographs of infolded nuclei from cultured hippocampal neurons $(\boldsymbol{a}-\boldsymbol{c})$ and from neurons from the $\mathrm{CA}$ pyramidal cell layer of rat hippocampal slices $(\boldsymbol{d}-\boldsymbol{f})$. The close-ups in cand $\boldsymbol{f}$ show that the invaginations are lined by both the inner and outer nuclear membranes. Scale bars, $1 \mu \mathrm{m}$.

\section{Results}

Morphological analysis and 3D image reconstruction of hippocampal cell nuclei

To visualize the structure of cell nuclei, we used a recently developed algorithm that allows 3D image reconstruction of cell organelles from optical sections generated using a laser-scanning confocal microscope (Queisser et al., 2008; see also supplemental material, available at www.jneurosci.org). For the microscopy analysis, cultured hippocampal neurons were fixed and subjected to immunocytochemistry using an antibody to lamin B that decorates the inner nuclear envelope (Fig. 1A) (Goldman et al., 2002). Stacks of confocal images were processed using a nonlinear anisotropic diffusion filter (Broser et al., 2004) and a clustersegmentation process (Otsu-segmentation algorithm) (Otsu,
1979), from which a mathematical surface grid could be created, that represents the nuclear lamina. A total of 102 nuclei were reconstructed. We found that $\sim 30 \%$ of the nuclei of cultured hippocampal neurons are not near-spherical but have a complex infolded shape. Typical examples of $3 \mathrm{D}$ reconstructed hippocampal nuclei are shown in Figure $1 B$. A quantitative analysis of the nuclear geometry in hippocampal tissue of adult rats revealed that $\sim 4 \%$ of all nuclei in the CA1 pyramidal cell layer showed large invaginations of the nuclear envelope. Examples of electron micrographs of nuclei from the CA1 pyramidal cell layer of rat hippocampal slices and, for comparison, from cultured hippocampal neurons are shown in Figure 2. A quantitative analysis using brain tissue from postnatal day 5 (P5) rats revealed a similar percentage of infolded nuclei in the CA1 pyramidal layer of the hippocampus; a typical image of a hippocampal section from a P5 rat that was used for the quantitative analysis is shown in supplemental Figure 1, available at www.jneurosci.org as supplemental material. The difference between the incidence of infoldings in cultured neurons and in vivo may be due to the activity states of these neurons (see below).

During the course of the analysis of P5 brains, we noticed many irregularly shaped nuclei within the subcallosal zone (SCZ), a prominent cell layer between the hippocampus and the corpus callosum. In $\sim 40-60 \%$ of these cells, the nuclei were either highly infolded or even consisted of two or more lobes connected by thin bridges that resemble envelopelimited chromatin sheets (Olins et al., 1998) (supplemental Fig. 2, available at www.jneurosci.org as supplemental material). The SCZ as well as the related brain structure, the subventricular zone (SVZ) contain a mixed population of cells including glial cells, neuroblasts, and putative stem cells, some of which are known to have nuclei with deep invaginations (Doetsch et al., 1997; Seri et al., 2006).

To investigate the possibility that only the inner (and not the outer) nuclear envelope invades the cell nucleus to create an intranuclear reticulum [previously termed nucleoplasmic reticulum (Echevarría et al., 2003)], we analyzed hippocampal nuclei by electron microscopy. Electron micrographs obtained from both cultured hippocampal neurons and hippocampal slices of rat brains revealed that all clefts including those that dive deeply into the nucleus are lined by two closely juxtaposed membranes representing the inner and outer nuclear envelope (Fig. 2). These structures have some resemblance to the indentations of the nuclear membranes and grooves observed in several cell types in the primate and rodent hippocampus (Ribak and Seress, 1983; Frotscher et al., 1988; Soriano et al., 1990), onion epidermal cells 
A

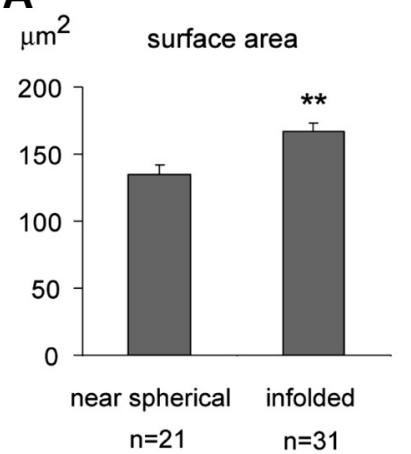

B
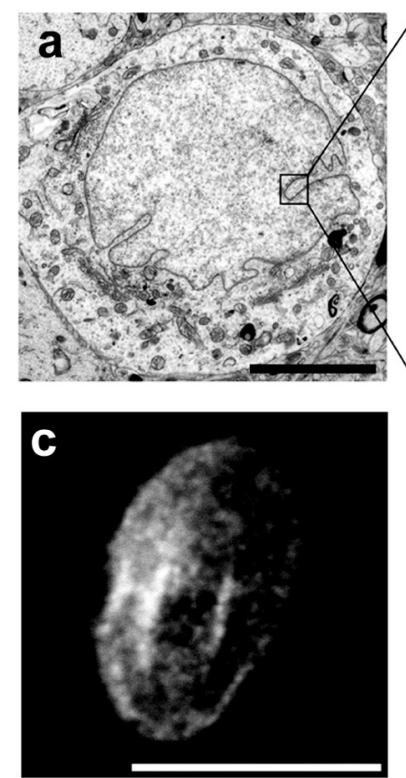

e Mab414 imunoreactivity

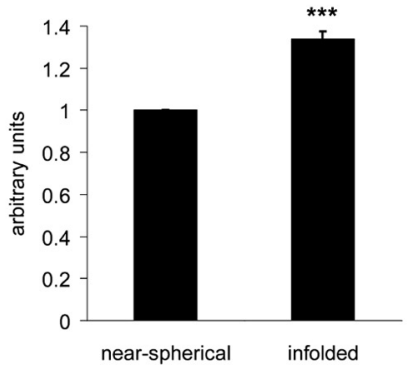

C

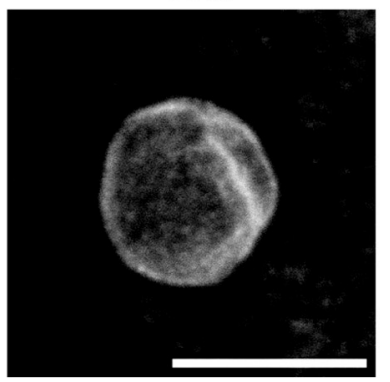

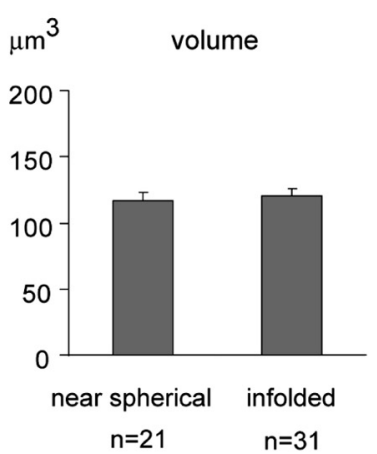
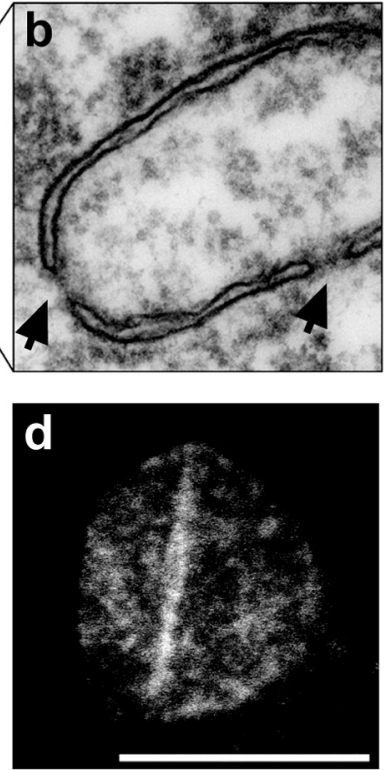

f

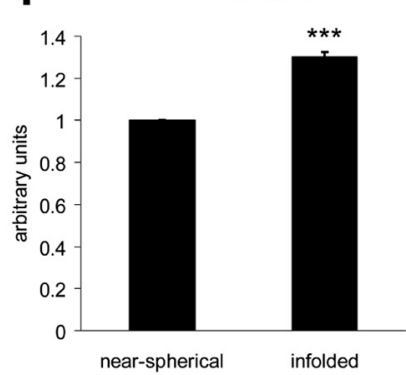

CA3

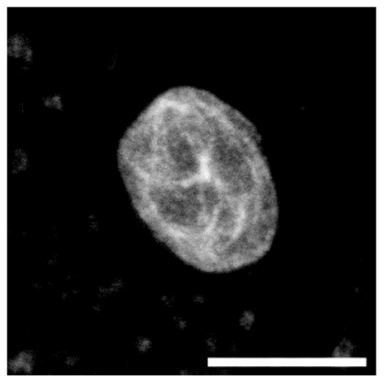

Figure 3. Infolded nuclei have a larger surface and more nuclear pore complexes than nearspherical nuclei. $\boldsymbol{A}$, Analysis of the surface (left panel) and volume (right panel) of 3D reconstructed near-spherical and infolded nuclei. Statistically significant differences (two-tailed independent samples $t$ test) are indicated with asterisks $\left({ }^{* *} p<0.005\right)$. Error bars indicate SEM. $\boldsymbol{B}$, Electron micrograph of an infolded nucleus from the CA1 pyramidal cell layer of the rat

and tobacco culture cells (Collings et al., 2000), and also to alterations in nuclear architecture found following stress, injury, or aging (Honavar and Lantos, 1987; Lafarga et al., 1992; Borsello et al., 2002; Dorsey et al., 2006). However, they appear morphologically distinct from the tube-like structures found in HeLa cells and various other non-neuronal cell lines (Fricker et al., 1997) and the highly lobulated nuclei found in fibroblasts from patients with Hutchinson-Gilford Progeria Syndrome (Goldman et al., 2004). Our results indicate that the inner nuclear envelope does not form intranuclear cisterns in hippocampal neurons and thus the surface of the 3D images marks the border between the cytosol and the nucleus.

\section{Infolded nuclei have larger surfaces and increased nuclear pore complex immunoreactivity}

We next investigated quantitative differences between infolded and near-spherical nuclei. First, we determined the volume and surface of the nuclei. We found that the volume of infolded and near-spherical nuclei was similar; however, infolded nuclei have a $23.8 \pm 5.4 \%$ larger surface area (Fig. $3 A$ ). Electron microscopy revealed that nuclear infoldings contain nuclear pore complexes (NPCs) (Fig. 3Ba,b), raising the possibility that an increased nuclear surface is accompanied by an increased number of NPCs. To investigate this, immunostaining experiments were done using the NPC antibody Mab414 and an antibody to NUP93, which is part of the NPC (Lim and Fahrenkrog, 2006). Examples of projections from confocal stacks showing NPC immunoreactivity in cultured hippocampal neurons obtained with these monoclonal antibodies are shown in Figure $3 B, c$ and $d$. The punctate nature of the NPC immunoreactivity was evident after processing of Mab414 immunostaining images with a deconvolution algorithm (data not shown). The quantified NPC immunostaining signals reflect the number of NPC expressed in a given nucleus (for details on the quantification of immunostaining experiments see Materials and Methods). By comparing NPC immunoreactivities, we obtained the relative abundance of NPCs in near-spherical versus infolded nuclei. For the two different antibodies, we observed significantly more NPC immunoreactivity in infolded nuclei compared with near-spherical nuclei (Fig. 3Be,f). This indicates that the increase in nuclear surface is accompanied by a similar increase in the number of NPCs, thus keeping the NPC density constant. We also analyzed NPCs in acute rat hippocampal slices. NPC immunostaining experiments with Mab414 identified infolded nuclei in the pyramidal cell layers of CA1 and CA3 (Fig. 3C).

\section{Infoldings generate nuclear signaling microdomains}

The differences in the amount of NPCs, nuclear surface area, and distances between cytosolic and nuclear sites observed in infolded versus near-spherical nuclei may be particularly relevant for diffusion in and out of the nucleus. We therefore used mathematical

\section{$\leftarrow$}

hippocampus $(\boldsymbol{a})$ and close-up $(\boldsymbol{b})$ of a nuclear infolding containing nuclear pore complexes indicated by arrows. Scale bar, $5 \mu \mathrm{m}$. Examples of projections from confocal stacks showing NPC immunoreactivity in cultured hippocampal neurons obtained with Mab414 (c) and antiNUP93 (d) monoclonal antibodies; scale bars, $10 \mu \mathrm{m}$. Quantitative analysis of the NPC immunoreactivity obtained with Mab414 $(\boldsymbol{e})$ and anti-NUP93 $(\boldsymbol{f})$ monoclonal antibodies in nearspherical and infolded nuclei. The results from 4 independent experiments are shown (total number of nuclei analyzed, $n=579$ ). Statistically significant differences (2-tailed independent samples $t$ test) are indicated with asterisks ( $\left.{ }^{* *} p<0.001\right)$. Error bars indicate SEM. C, NPC immunoreactivity obtained with Mab414 in nuclei from neurons from the CA1 and the CA3 pyramidal cell layer of rat hippocampal slices. Scale bars, $10 \mu \mathrm{m}$. 
A

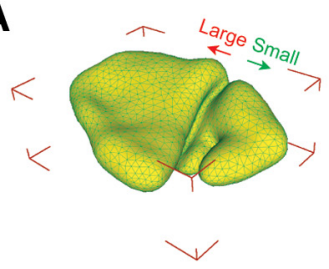

B

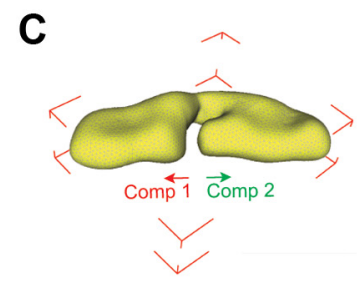

D

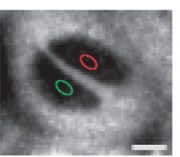

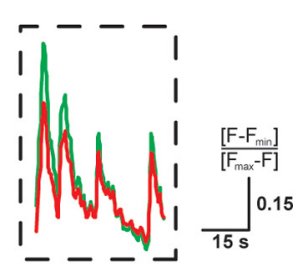

Experiment
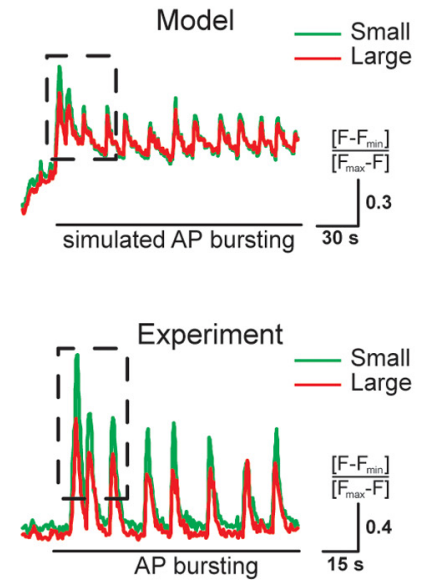
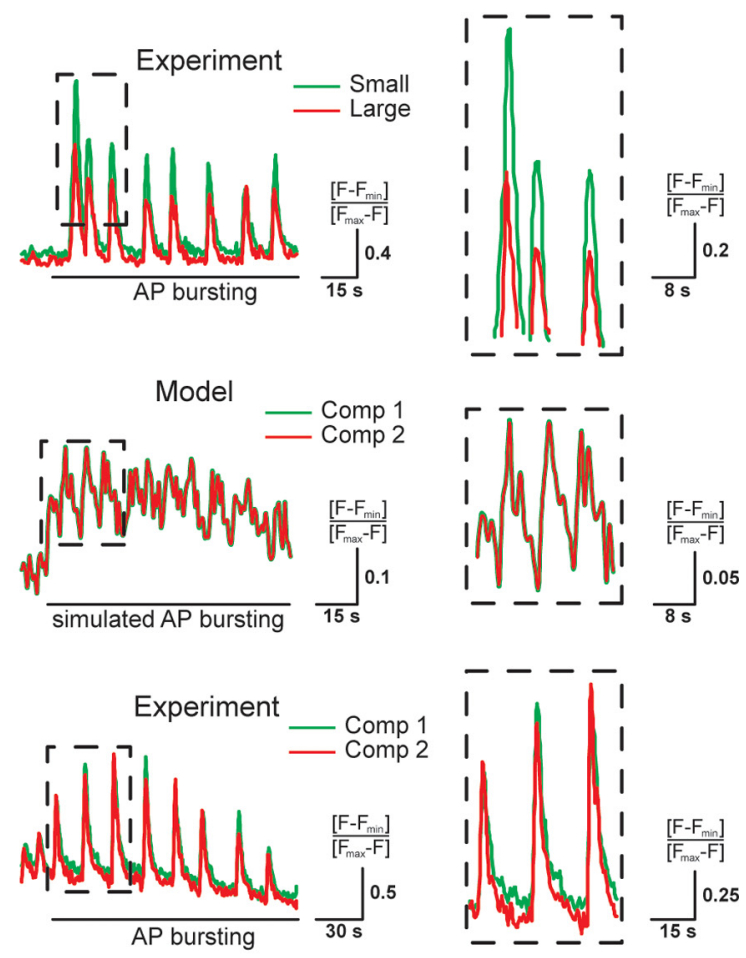

E
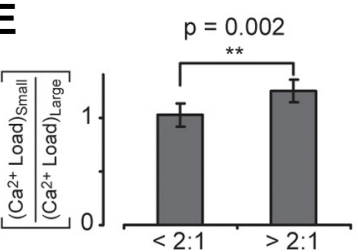

Figure 4. Dynamics of nuclear calcium signaling in differently sized and nearly equally sized compartments of infolded nuclei. For calcium imaging experiments, cultured hippocampal neurons were exposed to the $G A B A_{A}$ receptor blocker bicuculline $(50 \mu \mathrm{M})$; this treatment leads to bursts of AP firing and generates periodic calcium transients in the cytosol and in the nucleus (Hardingham et al., 2001a; Arnold et al., 2005). Image acquisition was done at a rate of $1.5 \mathrm{~Hz}$ with a confocal microscope. Calcium signals were measured using Fluo-4 at a cross-section approximately in the middle of both nuclear compartments as shown in the left panels of $\boldsymbol{B}$ and $\boldsymbol{D}$. The dashed boxes (in $\boldsymbol{A}-\boldsymbol{D}$ ) show an expanded view of 3-4 peaks of the oscillating calcium signals. Details of the mathematical modeling are described in the supplemental material, available at www.jneurosci.org. $\boldsymbol{A}$, Image of a 3D reconstructed nucleus with a large and a small compartment (left panel) that was used for mathematical modeling of calcium loads (right panel). Modeled time courses of the nuclear calcium load in the small (green trace) and the large compartment (red trace) in response to an experimentally measured cytosolic calcium transient (CCT). B, Photomicrograph of an ER-Tracker labeled cultured hippocampal neuron (left panel) illustrating the two differently sized nuclear compartments. Nuclear calcium measurements (right panel) were made in the nuclear regions of interest (ROls) indicated by the green and the red ellipse. Scale bar, $5 \mu \mathrm{m}$. Time courses of periodic nuclear calcium transients measured in the small (green trace) and the large compartment (red trace) of the infolded nucleus shown in the left panel. The area of the large compartment was 3.4-fold bigger than that of the small compartment. C, Image of a 3D reconstructed nucleus with two nearly equally sized compartments (left panel) that was used for mathematical modeling of calcium loads (right panel). Modeled time courses of the nuclear calcium load in compartment 1 (Comp 1, green trace) and compartment 2 (Comp 2, red trace) in response to an experimentally measured (CT. D, Photomicrograph of an ER-Tracker labeled cultured hippocampal neuron (left panel) with two nearly equally sized nuclear compartments. Nuclear calcium measurements (right panel) were made in the nuclear Rols indicated by the green and the red ellipse. Scale bar, $5 \mu \mathrm{m}$. Time courses of periodic nuclear calcium transients measured in compartment 1 (Comp 1, green trace) and compartment 2 (Comp 2, red trace) of the infolded nucleus shown in the left panel. The ratio of the areas of the two compartments was 1:1.1. E, Summary of the ratios of the calcium load measured in the small and the large compartments. To determine calcium load, calcium imaging traces were integrated over a period of $60 \mathrm{~s}$ of bicuculline treatment. The calcium load ratios (small/large compartment) were pooled into groups of compartment size ratios (large/small) $<2: 1$ and $>2: 1$. Error bars represent means \pm SEM (3 independent experiments: $<2: 1$ ( $n, 17$ cells); $>2: 1$ ( $n, 26$ cells). Statistical comparisons were made using the independent one-tailed Student's $t$ test.

modeling to test the influence of the different aspects of the nuclear geometry on the dynamics of calcium transients in the cell nucleus following increases in the cytosolic calcium concentration. Nuclear calcium signaling was chosen because it controls gene expression mediated by the CREB/CBP transcription factor complex (Bading et al., 1993; Hardingham et al., 1997, 2001a; Chawla et al., 1998) that is important for adaptive processes in the brain including neuronal survival, plasticity, and learning (Milner et al., 1998; Bading, 2000; Lonze and Ginty, 2002; Limbäck-Stokin et al., 2004; Papadia et al., 2005). Nuclear calcium transients are triggered by calcium entry into neurons either through synaptic NMDA receptors or L-type voltage-gated calcium channels (Hardingham et al., 2001a, 2002). Through a still unresolved mechanism, synaptic activity-induced calcium signals travel to the cell soma where they readily invade the nucleus most likely through NPCs (Nakazawa and Murphy, 1999; Hardingham et al., 2001a; Power and Sah, 2002; Raymond and Redman, 2006; Watanabe et al., 2006; Johenning and Holthoff, 2007; Eder and Bading, 2007 Hagenston et al., 2008). In rat hippocampal neurons and amphibian sympathetic neurons, the nuclear compartment border does not sustain a calcium gradient across the nuclear envelope (O'Malley, 1994; Eder and Bading, 2007), although in other cell types the nucleus may be insulated from cytosolic calcium transients (al-Mohanna et al., 1994; Badminton et al., 1996). Mathematical modeling of nuclear calcium dynamics revealed that infoldings divide the nucleus into compartments that can function as nuclear signaling microdomains (Figs. 4 and 5).

To assess the effect of infoldinginduced compartmentalization on calcium signaling in the nucleus, mathematical models were developed to run systematic simulations of calcium diffusion between the cytosol and the nucleus through NPCs (for details of the mathematical modeling see supplemental material, available at www.jneurosci.org). The model is based on a diffusion equation, a partial differential equation, which models the propagation of calcium signals into and within the nucleus. The nuclear geometry was generated from confocal microscopy data, processed with the $3 \mathrm{D}$ reconstruction tools outlined above and in the supplemental material, available at www.jneurosci.org. As boundary conditions for the diffusion equation, we developed a method to input, experimentally measured cytosolic 
calcium transients (CCTs) directly into the simulation software $U G$ (Bastian et al., 2000), which allows mathematical modeling on highly unstructured geometries. In brief, mathematical modeling of calcium signaling in the nucleus was done by supplying real, experimentally measured cytosolic calcium signals as input to the diffusion equation and applying it to $3 \mathrm{D}$ reconstructions of real nuclear geometries. Nuclear calcium signaling was modeled in infolded nuclei with either differently sized or nearly equally sized compartments (Fig. 4A,C). Parallel to the modeling experiments, we performed confocal calcium imaging experiments with cultured hippocampal neurons containing nuclei with either differently sized or nearly equally sized compartments (Fig. $4 B, D$ ).

Simulations showed that compartments, formed by the infolding of the nuclear envelope, exhibit different calcium signals depending on their size. Small nuclear compartments show larger amplitude calcium signals compared with those of large compartments of the same nucleus (Fig. $4 A$ ), most likely due to faster rise and decay times of the signal in smaller compartments. Differences in the rise and decay times of calcium signals have previously been reported in small non-nuclear subcellular compartments such as dendrites, spines, and presynaptic terminals (Augustine and Neher, 1992; Regehr and Tank, 1994; Yuste et al., 2000; Helmchen, 2002). In contrast, calcium signals are equivalent in nearly equally sized nuclear compartments of the same nucleus (Fig. 4C). Similar results were observed in calcium imaging experiments. Here too, small compartments of infolded nuclei showed larger amplitude calcium signals than large compartments of the same nucleus (Fig. $4 B$ ), whereas in nuclei with nearly equally sized nuclear compartments the calcium signals were similar in the two compartments (Fig. 4D). Raw fluorescence of Fluo-4 in large and small compartments was equal suggesting that compartmental differences in dye concentration and thus calcium buffering did not exist. We quantified the observed effects by allocating cells with infolded nuclei into two groups, those with similar and those with dissimilar nuclear compartment sizes (large compartment size to small compartment size ratios of $<2: 1$ and $>2: 1$, respectively). Relative to the larger compartments, the smaller compartments of neurons with compartment size ratios of $>2: 1$ showed significantly higher calcium levels during bursts of ac-
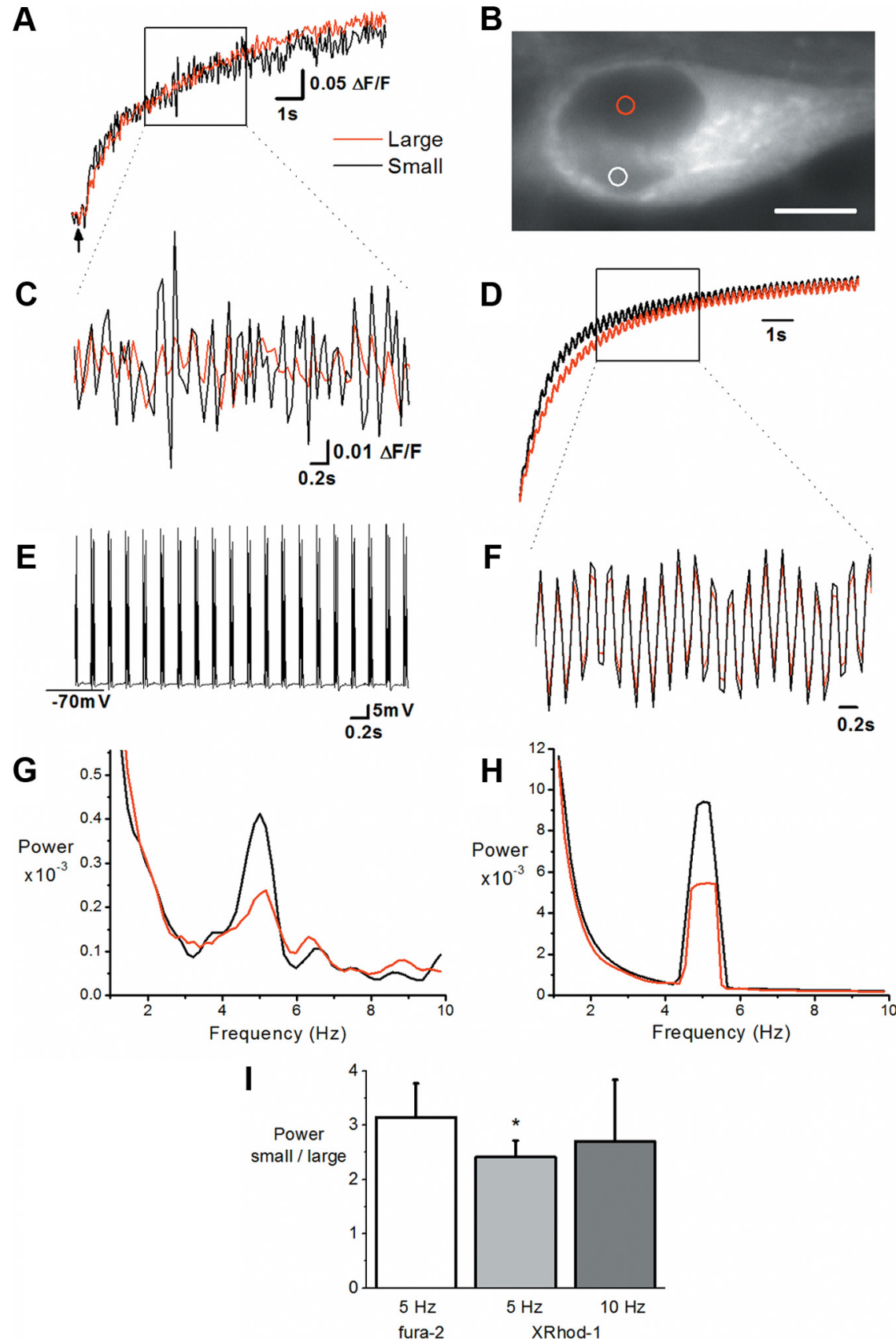

Figure 5. Frequency information in calcium signals is preserved better by smaller nuclear compartments. $\boldsymbol{A}, \boldsymbol{B}, \mathrm{X}$-Rhod-1 calcium signals measured at $21 \mathrm{~Hz}$ from small equally sized regions of interest in the center of the small and large nuclear compartments of a cultured hippocampal neuron labeled with ER-Tracker blue-white DPX shown in $\boldsymbol{B}$. Calcium levels rise in response to bursting which began at the point indicated by the arrow. Heterogeneous compartment size was apparent at all focal planes. Scale bar, $5 \mu \mathrm{m}$. C, Calcium signals (high-pass filtered at $1 \mathrm{~Hz}$ ) over the period indicated in $\boldsymbol{A}$. D, A simulated calcium signal in a small and a large nuclear compartment of a model nucleus was generated as a response to a hypothetical signal input. This input was created from a second order exponential fit to the somatic response of the real neuron in $\boldsymbol{A}$, with a superimposed oscillation at $5 \mathrm{~Hz}$. The simulated calcium signal was calculated considering the total volume of each compartment. $\boldsymbol{E}$, The membrane potential shows $5 \mathrm{~Hz}$ bursting recorded in parallel with the calcium signal over the same time period as in $\boldsymbol{C}$. Bursting was induced with current injection applied via whole-cell patch clamp in $5 \mathrm{~Hz}$ bursts ( 1 burst $=5$ injections at 100 $\mathrm{Hz}$ ). $\boldsymbol{F}$, Calcium signals (high-pass filtered at $1 \mathrm{~Hz}$ ) from the model nucleus over the period indicated in $\boldsymbol{D}$. $\boldsymbol{G}, \boldsymbol{H}$, Power spectral density plots computed by the multitaper method (FFT size, 128, 5 data tapers). A clear peak is apparent around 5 $\mathrm{Hz}$ in the calcium signals of all compartments in both the real neuron $(\boldsymbol{G})$ and the model nucleus $(\boldsymbol{H})$. Note the larger amplitude of this peak in the smaller compartments in both real and model nucleus. Sampling frequency and analysis parameters of modeling and experimental data are identical. I, Summary histogram showing the normalized power peak in small relative to large compartments in response to bursting at $5 \mathrm{~Hz}$ and $10 \mathrm{~Hz}$ using X-Rhod- $1(5 \mathrm{~Hz}: n=9,10 \mathrm{~Hz}: n=$ 5) or fura-2 (5 Hz: $n=8)$. ${ }^{*} p<0.05$ paired Student's $t$ test. 
tion potential (AP) firing than neurons with nuclear compartment size ratios of $<2: 1$ (Fig. $4 E$ ).

These results indicate that the geometry of the nucleus influences the relay of calcium signals to the nucleus. Infoldings of the nuclear envelope separate the nucleus into microdomains that can be seen as functional units of the nucleus, which generate distinct calcium signals. Due to reduced diffusion distances in small microdomains, small compartments generate larger calcium signals, which are more likely to be above threshold for calcium-regulated events than calcium signals in large microdomains. Our modeling data indicated faster rise and decay times of calcium signals in small compartments, which predicts that calcium signals in small compartments more accurately follow an oscillating calcium signal originating in the soma, especially at higher frequencies. Thus, the transmission of somatic calcium signals to small nuclear compartments may help to preserve information contained in the frequency of the signal.

\section{Improved temporal resolution of multiple calcium signals in smaller nuclear compartments}

To examine the temporal resolution of an oscillating calcium signal, we compared modeling predictions generated from an artificial somatic calcium signal with experimentally observed data generated from a similar somatic signal. Patch-clamp recordings combined with calcium imaging using X-Rhod-1 (Fig. 5 ) or the ratiometric calcium indicator, fura-2 (supplemental Fig. 3 , available at www.jneurosci.org as supplemental material) were made from neurons with infolded nuclei. Current injection was used to depolarize the membrane to generate a series of action potentials (i.e., a burst) at specified frequencies and burst intervals (for details, see supplemental material, available at www. jneurosci.org). These bursts generated somatic calcium signals, which presumably originated predominantly from the activation of voltage-operated calcium channels in the plasma membrane and traversed the nuclear envelope to enter each nuclear compartment. Recurrent bursting at 5 and $10 \mathrm{~Hz}$ was seen to generate a sharp rise in nuclear calcium levels over the $10-15 \mathrm{~s}$ of stimulation (Fig. 5A; supplemental Fig. $3 A$, available at www.jneurosci. org as supplemental material). This nuclear calcium signal also showed a higher frequency component corresponding to the stimulation frequency, which was more visible after high-pass filtering ( $>1 \mathrm{~Hz}$, Fig. $5 C$; supplemental Fig. $3 C$, available at www. jneurosci.org as supplemental material). Unfiltered signals were analyzed with a fast Fourier transform (FFT) to resolve the power of the signal across the frequency spectrum. Recordings from neurons with similarly sized nuclear compartments showed no difference in the power of calcium signals generated at $5 \mathrm{~Hz}$ ( $n=3$ with fura-2) whereas neurons with unequally sized compartments showed either no difference in power $(n=5$ with X-Rhod-1; $n=3$ with fura-2) or a larger power in the smaller compartment ( $n=4$ with X-Rhod-1; $n=5$ with fura-2) for signals generated at $5 \mathrm{~Hz}$ (Fig. 5G,I; supplemental Fig. $3 E$, available at www.jneurosci.org as supplemental material). Oscillating calcium signals were also larger in smaller compartments than in larger compartments of some nuclei when the stimulation frequency was increased to $10 \mathrm{~Hz}(n=3$, no difference; $n=2$ larger power in smaller compartment; all with X-Rhod-1; Fig. 5I). While these experiments were done at room temperature, similar results were obtained at $32-34^{\circ} \mathrm{C}$ (data not shown). Similar results were also obtained when identical analysis procedures were applied to simulation data generated from an artificial somatic calcium signal of a similar sampling frequency and kinetic (Fig. $5 D, F, H)$. Calcium oscillations were larger in the small than in the large nuclear compartment with a relative difference in the power of this signal comparable to that observed experimentally in live cells (compare Fig. 5G,H). Thus, both experiment and model show that frequency information in calcium signals is preserved better by smaller nuclear compartments and that small compartments of infolded nuclei better resolve a calcium signal originating in the soma, which oscillates in the $5-10 \mathrm{~Hz}$ range.

\section{Activation of synaptic NMDA receptors promote the formation of nuclear infoldings}

We next investigated the possibility that nuclear infoldings are dynamic structures regulated by intracellular signaling pathways. Nuclear geometry was assessed by fluorescence microscopy in cultured hippocampal neurons following immunocytochemical labeling of the nuclear lamina using the antibody to lamin B. We found that indeed electrical activity can dramatically change the nuclear geometry. We focused in particular on electrical stimulation paradigms that activate calcium entry through NMDA receptors that play a central role in both the physiology and pathology of neurons (Hardingham and Bading, 2003). We found that stimulation of synaptic NMDA receptors increased the percentage of infolded nuclei. Synaptic NMDA receptors were stimulated by exposing hippocampal neurons to the $\mathrm{GABA}_{\mathrm{A}}$ receptor antagonist bicuculline. Because the hippocampal network contains $\sim 11 \%$ GABA-ergic interneurons that impose a tonic inhibition onto the network, removal of $\mathrm{GABA}_{\mathrm{A}}$ receptor activity leads to bursts of AP firing (Hardingham et al., 2001b; Arnold et al., 2005). AP bursting causes calcium entry through synaptic NMDA receptors, generates robust calcium transients in the cytosol and nucleus, activates gene transcription, and promotes neuronal plasticity and survival (Hardingham et al., 2002; Hardingham and Bading, 2003; Arnold et al., 2005; Lee et al., 2005; Papadia et al., 2005). Analysis of the nuclear geometry showed that AP bursting rapidly increased the number of infolded nuclei (Fig. 6A-C). We also used time-lapse confocal imaging to visualize the formation of nuclear infoldings. For those experiments we labeled the membranes of cultured hippocampal neurons with the fluorescent stain, DiD, recorded over time confocal stacks covering the entire nucleus and projected the images for each time point into one plane. Supplemental Figure 4, available at www.jneurosci.org as supplemental material, illustrates an example of a hippocampal neuron that on AP bursting formed nuclear infoldings. The induction of nuclear infoldings following AP bursting was dependent on NMDA receptor activation and was inhibited by the NMDA receptor antagonist, MK-801 (Fig. 6C).

To investigate whether the presence of nuclear infoldings in already $\sim 30 \%$ of hippocampal neurons was due to ongoing electrical activity during the first week of cell culture, we blocked all glutamatergic synaptic transmission in the hippocampal network during this culturing period by including kynurenate, a nonselective glutamate receptor antagonist, and $11 \mathrm{mM} \mathrm{MgCl}_{2}$ in the culture medium. Under these conditions far fewer neurons have nuclear infoldings although infoldings can be rapidly induced in these cells by subsequent induction of AP bursting (Fig. $6 \mathrm{~B}$ ). This indicates that indeed neuronal activity (both basal and evoked activity) is a prime regulator of nuclear geometry.

\section{Rapid loss of nuclear infoldings following stimulation of extrasynaptic NMDA receptors}

In contrast to the effects of AP bursting and synaptic NMDA receptors on nuclear geometry, the stimulation of extrasynaptic NMDA receptors using bath application of NMDA led to a rapid 
loss of nuclear infoldings. Within 15-30 min of NMDA bath application virtually all infolded nuclei were transformed into a near-spherical shape (Fig. 6D). To monitor the behavior of nuclear infoldings in real time we transfected hippocampal neurons with an expression vector for a fusion protein containing human lamin B1 and GFP (lamin B-GFP) (Daigle et al., 2001). High levels of lamin B-GFP expression caused neuronal nuclei to acquire a highly lobulated shape (data not shown), which resembles to some extent the morphology of nuclei found in aged nonneuronal cell types in Caenorhabditis elegans (Haithcock et al., 2005) and in Hutchinson-Gilford Progeria Syndrome, an accelerated aging disease in humans caused by mutations in lamin A (Eriksson et al., 2003; Mounkes et al., 2003; Goldman et al., 2004; Scaffidi and Misteli, 2006). We therefore selected for the analysis neurons that expressed low levels of lamin B-GFP and did not show a lobulated nuclear shape. Exposure of those cells to $50 \mu \mathrm{M}$ NMDA led to a rapid loss of nuclear infoldings (Fig. 6E).

The striking differences between the effects of AP bursting and bath application of NMDA suggest that synaptic and extrasynaptic NMDA receptors antagonistically control nuclear geometry. However, it is also possible that differences in the amplitude and/or kinetics of the calcium transients evoked by the two stimulation paradigms rather than the location of the NMDA receptor activated explain the result. AP bursting generates intermittent calcium signals, whereas bath application of NMDA triggers an intense sustained increase in calcium levels (see, for example, Hardingham et al., 2001a, 2002; Bengtson et al., 2008). We therefore sought to establish a stimulation paradigm that activates synaptic NMDA receptors and generates sustained calcium transients. This was achieved by the use of 4-aminopyridine (4-AP), a potassium channel blocker that increases the frequency of bicuculline-induced AP bursting in hippocampal networks (Hardingham et al., 2001a, 2002) causing sustained increases in calcium levels very similar in amplitude, duration, and net calcium influx (area under the curve) to those obtained with bath application of NMDA (Fig. $6 F, G$ ). However, the effects of bicuculline/4-AP and bath application of NMDA on nuclear geometry were dramatically different: bicuculline/4-AP increased whereas bath application of NMDA decreased the percentage of hippocampal neurons with infolded nuclei (Fig. $6 H, I)$. These results indicate that, indeed, the location of the NMDA receptor activated (synaptic vs extrasynaptic) determines whether nuclear infoldings are being newly formed or lost.
B

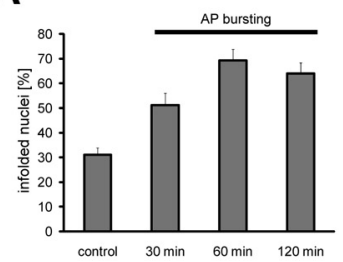

D

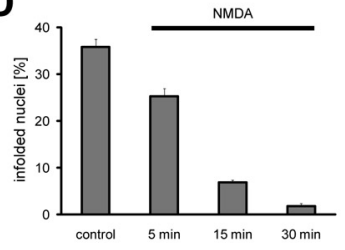

$\mathbf{F}$

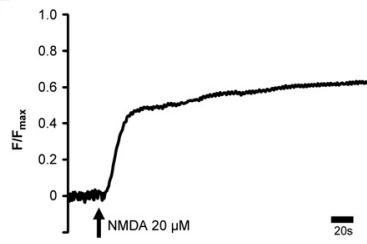

G

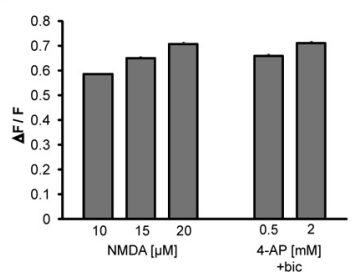

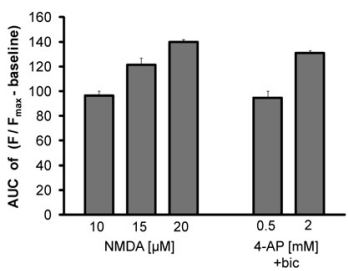

C

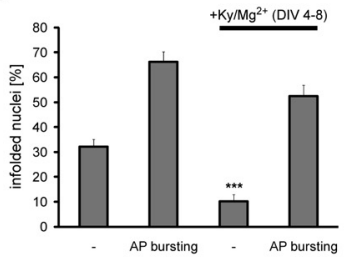

E

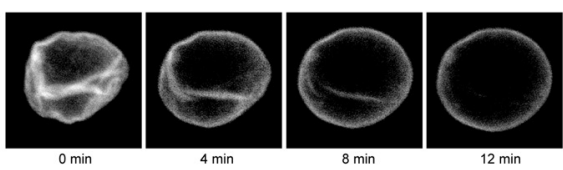

H
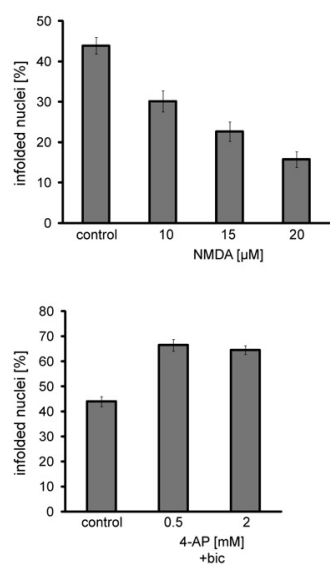

Figure 6. Control of nuclear geometry by synaptic and extrasynaptic NMDA receptors. $A$, Analysis of the percentage of infolded nuclei in cultured hippocampal neurons following bicuculline $(50 \mu \mathrm{m})$ induced AP bursting for the indicated times. $\boldsymbol{B}$, Analysis of the percentage of infolded nuclei in hippocampal neurons grown between day in vitro (DIV) 4 and 8 in the absence or presence of $1 \mathrm{~mm}$ kynurenate and $11 \mathrm{~mm} \mathrm{MgCl}\left(\mathrm{KyMg}^{2+}\right)$; this treatment blocks glutamatergic synaptic transmission and NMDA receptors. AP bursting was induced with bicuculline $(50 \mu \mathrm{m})$ for $1 \mathrm{~h}$ on DIV 11. Statistically significant differences (two-tailed independent samples $t$ test) are indicated with asterisks $\left({ }^{* * *} p<0.001\right)$. Error bars indicate SEM. C, Analysis of the percentage of infolded nuclei in cultured hippocampal neurons following bicuculline $(50 \mu \mathrm{m})$ induced AP bursting for $1 \mathrm{~h}$ in the absence or presence of MK-801 (20 $\mu \mathrm{M}$ ). MK-801 was added 5 min before stimulation. Statistically significant differences (two-tailed independent samples $t$ test) are indicated with asterisks $\left({ }^{* * *} p<0.001\right)$. Error bars indicate SEM. $\boldsymbol{D}$. Analysis of the percentage of infolded nuclei in cultured hippocampal neurons after bath application of NMDA $(50 \mu \mathrm{M})$ for the indicated times. Such treatment of hippocampal neurons with NMDA triggers pathways leading to cell death through the activation of extrasynaptic NMDA receptors (Hardingham et al., 2002). The stimulation of cell death pathways by treatment of cultured hippocampal neurons for 1 or $2 \mathrm{~h}$ with $100 \mathrm{~nm}$ staurosporine had no effect on the percentage of infolded nuclei (data not shown). $E$, Lamin B-GFP images (z projections from confocal stacks) of a nucleus from a cultured hippocampal neuron (transfected with a lamin B-GFP expression vector) taken before and after the indicated periods of bath application of NMDA $(50 \mu \mathrm{M})$. In the example shown, the infoldings of the nucleus disappeared within 12 min of NMDA application. $\boldsymbol{F}$, Calcium imaging of cultured hippocampal neurons following treatment with NMDA (20 $\mu \mathrm{M}$, left panel) or bicuculline (bic; $50 \mu \mathrm{m}$ ) plus 4-aminopyridine (4-AP; $2 \mathrm{~mm}$ ) (right panel). The arrows indicate the time point of stimulation. Imaging traces representing average signals obtained from 48 (bic/4-AP) and 46 (NMDA) neurons are shown. G, Summary of calcium imaging experiments in cultured hippocampal neurons. Calcium response amplitudes normalized to $F_{\max }$ and their integral over a 10 min response period (AUC, area under the curve) to the indicated treatments are shown. Number of cells analyzed was 1702 . $\boldsymbol{H}, \mathbf{I}$, Analysis of the percentage of infolded nuclei in cultured hippocampal neurons before (control) and $1 \mathrm{~h}$ after bath application of the indicated concentration of NMDA $(\boldsymbol{H})$ or $1 \mathrm{~h}$ after application of bicuculline (bic; $50 \mu \mathrm{M})$ and the indicated concentrations of 4-aminopyridine (4-AP) (I).

Analysis of glial cells present in hippocampal cultures revealed that $\sim 12 \%$ of GFAP-positive cells have nuclear infoldings. However, the infoldings are generally less prominent than those in hippocampal neurons (supplemental Fig. 5, available at www.jneurosci.org as supplemental material) and the percentage of infolded glial cell nuclei did not change after stimulation of hippocampal cultures with bicuculline (data not shown). 


\section{Activity-induced formation of nuclear infoldings requires ERK-MAP kinase signaling and protein synthesis}

One of the intracellular signaling pathways activated by synaptic activity and a localized calcium signal in the immediate vicinity of synaptic NMDA receptors is the ERK-MAP kinase cascade (Bading and Greenberg, 1991; Grewal et al., 1999; Hardingham et al., 2001b; Sweatt, 2004; Wiegert et al., 2007). To investigate whether this signaling pathway is important for NMDA receptordependent regulation of nuclear geometry, we pharmacologically blocked this pathway using MAP kinase/ERK kinase (MEK) inhibitors PD98059 or UO126. We found that indeed, PD98059 and UO126 blocked the signal-induced formation of infoldings (Fig. 7A). Thus, neuronal activity stimulates the formation of nuclear infoldings through a mechanism that is triggered by calcium entry through synaptic NMDA receptors and requires the ERK-MAP kinase signaling pathway. To investigate the persistence of newly formed infoldings, we first induced AP bursting for $1 \mathrm{~h}$, which was followed by treatment with tetrodotoxin (TTX) to stop all electrical activity (Fig. 7B). Under those conditions, most infoldings disappeared within $1-2 \mathrm{~h}$ of blocking activity (Fig. 7C, dashed line). However, if the neurons were induced to fire bursts of APs for prolonged periods of time (i.e., $40 \mathrm{~h}$ ) causing repeated activation of synaptic NMDA receptors, nuclear infoldings persisted for several hours even after neuronal activity was blocked with TTX (Fig. 7C, solid line). This indicates that activity-induced changes in nuclear shape are initially unstable but become more stable and independent of ongoing electrical activity during repeated stimulations. Since activity-induced, long-lasting structural and functional changes of neurons are often dependent on the synthesis of new proteins, we investigated the requirement of gene transcription and mRNA translation for activity-induced formation of nuclear infoldings. We found that two inhibitors of protein synthesis, anisomycin and cycloheximide, completely blocked the AP bursting-induced formation of new infoldings (Fig. $7 D, E$ ). In contrast, actinomycin D, an inhibitor of gene transcription did not prevent the increase in the percentage of infolded nuclei in cultured hippocampal neurons following AP bursting (Fig. 7D), and neither did anisomycin at a low concentration which did not inhibit mRNA translation but activated a stress response and caused phosphorylation of the p38 MAP kinase (data not shown). These results indicate that the translation of preexisting mRNAs is required for activity-induced formation of nuclear infoldings.

\section{Synaptic activity-induced phosphorylation of histone $\mathrm{H} 3$ at serine 10 correlates with the degree of nuclear infolding}

We next investigated whether the presence of nuclear infoldings correlates with transcription-relevant events. The phosphorylation of histone $\mathrm{H} 3$ at serine residue 10 is important for synaptic activity-induced chromatin remodeling and serves as an indicator of gene transcription (Brami-Cherrier et al., 2005, 2007). Histone $\mathrm{H} 3$ serine 10 phosphorylation is induced in hippocampal neurons in an activity-dependent manner (Chwang et al., 2007; Chandramohan et al., 2008) (see also Fig. $8 A, B$ ); this phosphorylation event is mediated by the mitogen-activated stress-kinases 1 and 2 (MSK1/2) (Soloaga et al., 2003), which are nuclear targets of the ERK-MAP kinase and the p38-MAP kinase cascades (Deak et al., 1998). To unearth a possible correlation between histone $\mathrm{H} 3$ phosphorylation at serine 10 and the degree of infolding, we performed immunocytochemical experiments using antibodies that bind to the serine 10 phosphorylated form of histone $\mathrm{H} 3$. In the same neurons, we assessed the nuclear geometry using antibodies to lamin A/C. Infolded nuclei were categorized as weakly
A

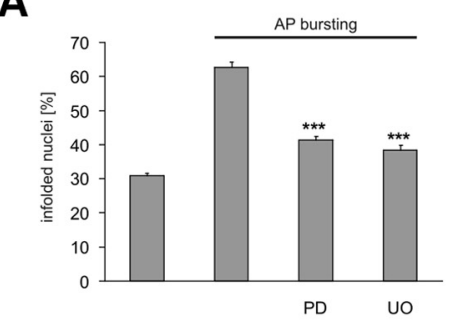

B

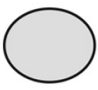

$\int \begin{aligned} & \text { AP bursting } \\ & 1 \mathrm{~h} \text { or } 40 \mathrm{~h}\end{aligned}$
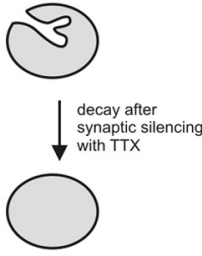

C

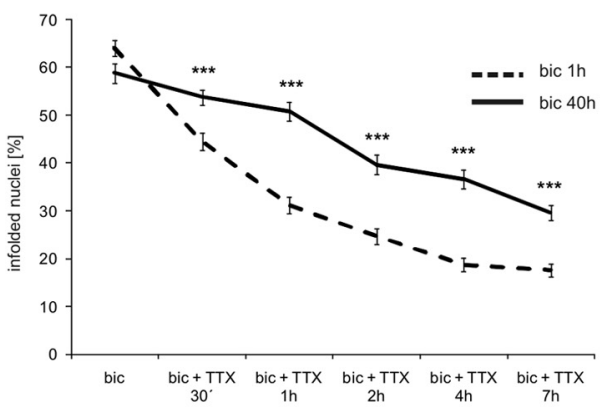

D

$\mathrm{E}$
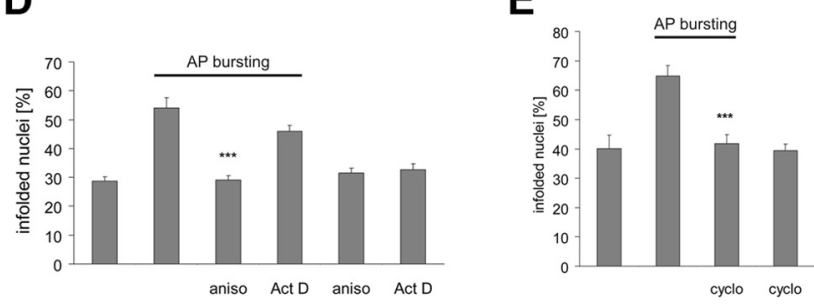

Figure 7. AP bursting-induced formation of infolded nuclei requires MAP kinase signaling and protein synthesis. $A$, Analysis of the percentage of infolded nuclei in cultured hippocampal neurons following bicuculline $(50 \mu \mathrm{M})$ induced AP bursting for $1 \mathrm{~h}$ in the absence or presence of PD98059 (PD; $50 \mu \mathrm{M}$ ) or U0126 (UD; $10 \mu \mathrm{M})$. PD98059 and U0126 were added 30 min before stimulation. The percentage of infolded nuclei in unstimulated hippocampal neurons was not affected by the pretreatment with PD98059 or U0126 (data not shown). Statistically significant differences (two-tailed independent samples $t$ test) are indicated with asterisks $\left({ }^{* *} p<\right.$ 0.001). Error bars indicate SEM. $B$, Schematic representation of the experiment in () to determine the stability of newly formed nuclear infoldings. $C$, Analysis of the percentage of infolded nuclei in cultured hippocampal neurons following treatment with $1 \mu \mathrm{m}$ tetrodotoxin (TTX) to block electrical activity. Infoldings were induced by a $1 \mathrm{~h}$ or a $40 \mathrm{~h}$ period of bicuculline (bic; 50 $\mu \mathrm{m}$ )-induced AP bursting before TTX treatment. Statistically significant differences (two-tailed independent samples $t$ test) are indicated with asterisks $\left({ }^{* * *} p<0.001\right)$. Error bars indicate SEM. $\boldsymbol{D}, \boldsymbol{E}$, Analysis of the percentage of infolded nuclei in cultured hippocampal neurons following bicuculline (50 $\mu \mathrm{m}$ )-induced AP bursting for $1 \mathrm{~h}$ in the presence or absence of anisomycin (aniso; $1 \mu \mathrm{g} / \mathrm{ml}$ ), actinomycin D (Act D; $10 \mu \mathrm{g} / \mathrm{ml}$ ), or cycloheximide (cyclo; $1 \mu \mathrm{g} / \mathrm{ml}$ ). Anisomycin, actinomycin $D$ and cycloheximide were added 30 min before stimulation; the percentage of infolded nuclei in unstimulated hippocampal neurons was not affected by the pretreatment with these inhibitors. Statistically significant differences (two-tailed independent samples $t$ test) are indicated with asterisks $\left({ }^{* *} p<0.001\right)$. Error bars indicate SEM.

infolded (only one invagination that spans at least one third of the size of the nucleus), moderately infolded (two invaginations) and highly infolded (three or more invaginations). To categorize the degree of nuclear infoldings anaglyph images were generated from maximum intensity $z$-stacks using ImageJ. Using 3D glasses, the 3D structure of each nucleus in an image stack was analyzed. This procedure enabled us to categorize the degree of nuclear infolding very accurately without the need for $3 \mathrm{D}$ reconstructions of individual nuclei. In control cells, $66 \%$ of the nuclei were near-spherical, $26 \%$ were weakly infolded, and $8 \%$ were moderately infolded. After $1 \mathrm{~h}$ of AP bursting, the fraction of 
near-spherical nuclei decreased to $25 \%$, whereas the fractions of weakly infolded, moderately infolded, and highly infolded nuclei increased to $34 \%, 25 \%$, and $16 \%$, respectively (Fig. $8 C$ ).

Using the antibody to the serine 10phosphorylated form of histone $\mathrm{H} 3$ we observed a robust increase in phospho$\mathrm{H} 3$ immunoreactivity $1 \mathrm{~h}$ after induction of AP bursting (Fig. $8 A, B$ ). Since the phospho-H3 staining varied considerably within the neuron population, we tested the possibility that the level of signalinduced histone phosphorylation is linked to nuclear geometry. Indeed, we found that after AP bursting, phospho-H3 immunoreactivity correlated with the complexity of nuclear infoldings, i.e., the strongest phospho-H3 signals were obtained in highly infolded nuclei whereas the weakest phospho-H3 signals were obtained in weakly infolded nuclei (Fig. 8D). Even in unstimulated controls, phospho-H3 immunoreactivity was significantly stronger in moderately infolded nuclei compared with near-spherical or lightly infolded nuclei (Fig. 8D). Intranuclear differences between small and large compartments were not detected. Given that the phosphorylation of histone $\mathrm{H} 3$ on serine 10 is catalyzed by MSK1/2 (Soloaga et al., 2003), we also investigated a possible correlation between MSK1/2 activation and the degree of infolding. Using an antibody to the activated (i.e., threonine 581 phosphorylated) form of MSK1, we found that AP bursting caused a robust increase in nuclear phospho-MSK1 immunoreactivity (Fig. $8 \mathrm{~B}$ ). Similar to the results obtained for histone $\mathrm{H} 3$ phosphorylation, we found that infolded nuclei showed significantly higher nuclear phospho-MSK1 immunoreactivity compared with near-spherical nuclei (Fig. $8 E$ ). These results establish a link between nuclear infoldings, the activation of the ERK-MAP kinase target MSK1, and the phosphorylation of histone $\mathrm{H} 3$ and suggest that nuclear geometry may be relevant for signal-induced chromatin remodeling and gene expression.

\section{Burst activity induces nuclear infoldings and histone $\mathrm{H} 3$} phosphorylation in hippocampal slices We finally investigated whether the synaptic activity-induced structural changes observed in dissociated hippocampal cultures also take place in an experimental system with at least partially preserved neuronal circuitry. We used organotypic hippocampal slice cultures that were exposed to bicuculline to induce AP bursting. Calcium imaging experiments using Oregon Green 488 BAPTA-1-AM (OGB-1) revealed that bicuculline treatment of the slices gave rise to periodically occurring intracellular calcium transients (Fig. $10 \mu \mathrm{m}$
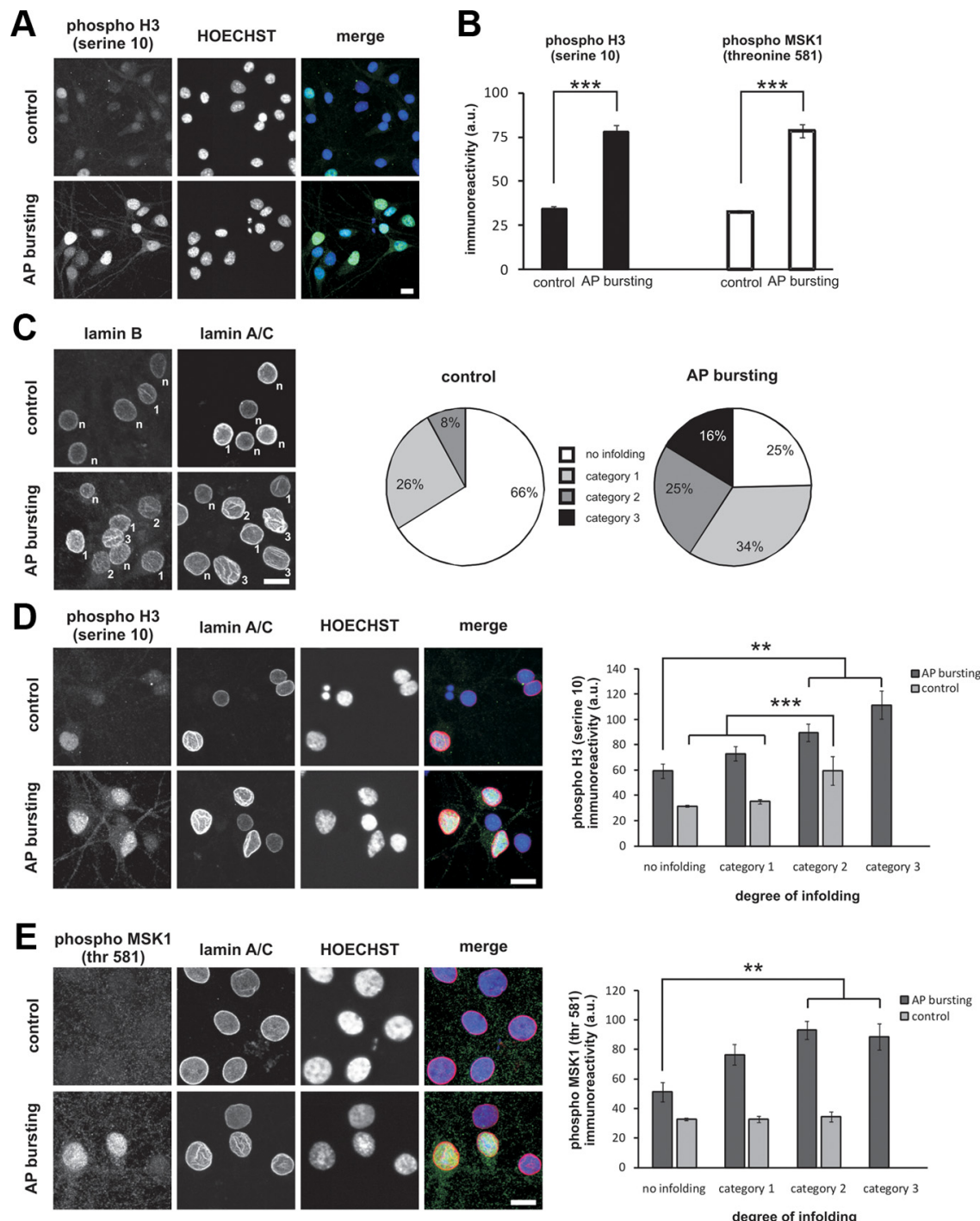

Figure 8. Link between nuclear geometry, activation of MSK1, and the phosphorylation of histone H3 at serine 10. $\boldsymbol{A}, \boldsymbol{B}$, Immunocytochemical analysis of histone $\mathrm{H} 3$ phosphorylation at serine $10(\boldsymbol{A}, \boldsymbol{B})$ and phosphorylation of MSK1 at threonine $581(\boldsymbol{B})$ in cultured hippocampal neurons treated for $1 \mathrm{~h}$ with vehicle (control) or bicuculline (50 $\mu \mathrm{m}$ ) to induce AP bursting. $\boldsymbol{A}$, Representative images of phospho- $\mathrm{H} 3$ labeled cells. $\boldsymbol{B}$, Histograms of the average nuclear phospho- $\mathrm{H} 3$ and phospho-MSK1 immunoreactivity measured as absolute 8 bit gray levels (Hoechst staining was used to identify nuclei). Number of nuclei analyzed: 198 (control, phospho-H3); 268 (AP bursting, phospho-H3); 130 (control, phospho-MSK1); 182 (AP bursting, phospho-MSK1). ${ }^{* * *} p<0.001$, independent samples $t$ test. Error bars indicate SEM. C, Assessment of the degree of nuclear infolding in hippocampal neurons treated for $1 \mathrm{~h}$ with vehicle (control) or with bicuculline $(50 \mu \mathrm{m})$ to induce AP bursting. Lamin B or lamin A/C immunoreactivity was used to categorize the nuclei as near-spherical/not infolded (n), weakly infolded (category 1), moderately infolded (category 2), and highly infolded (category 3); the criteria used are outlined in Results. Representative examples (left panel; category of infoldings is indicated for individual nuclei) and a pie chart summarizing the quantitative analysis (right panel) are shown; number of nuclei analyzed: 217 (control, no infolding), 85 (control, category 1), 26 (control, category 2), 111 (AP bursting, no infolding), 155 (AP bursting, category 1), 111 (AP bursting, category 2), 73 (AP bursting, category 3). D, E, Immunostaining analysis using antibodies to lamin A/C (to assess nuclear infoldings; Hoechst staining was used to identify nuclei) and antibodies to phospho-H3 $(\boldsymbol{D})$ or to phospho-MSK1 $(\boldsymbol{E})$ of hippocampal neurons treated for $1 \mathrm{~h}$ with vehicle (control) or with bicuculline (50 $\mu \mathrm{m}$ ) to induce AP bursting. Representative examples (left panels) and a summary of the quantitative analysis (right panels) are shown; for number of nuclei analyzed see $C .{ }^{* * *} p<0.001,{ }^{* *} p<0.005$, ANOVA followed by Tukey post hoc test. Error bars indicate SEM. Scale bars,

9A). Within $1 \mathrm{~h}$ after induction of burst activity with bicuculline, many nuclei of hippocampal neurons in the CA1 pyramidal cell layer had undergone dramatic changes in their geometry (Fig. $9 B, C)$. The percentage of infolded nuclei increased, in a TTXdependent manner, from $25 \% \pm 4.5 \%$ (category 1 ), $4 \% \pm 1.8 \%$ (category 2 ), and $1 \% \pm 0.5 \%$ (category 3 ) in the control conditions to $40 \% \pm 2.2 \%$ (category 1 ), $33 \% \pm 2.1 \%$ (category 2 ), and 
A
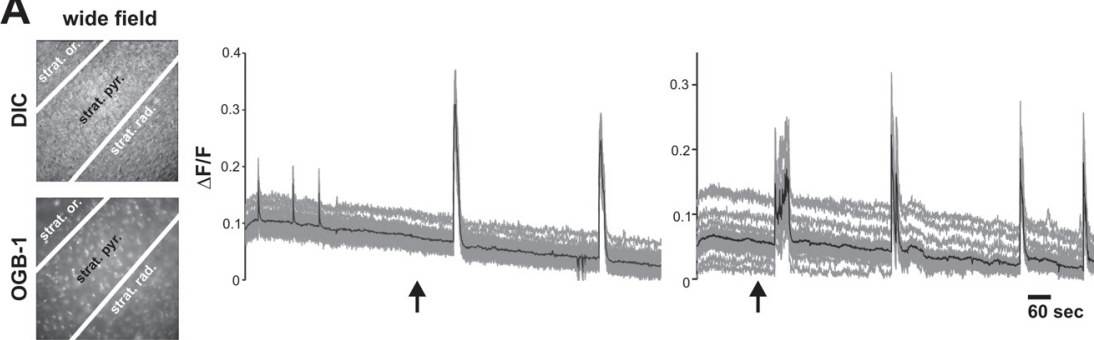

B
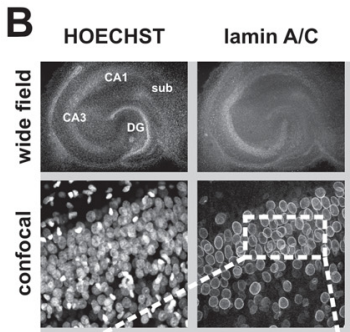

phospho H3 (serine 10)

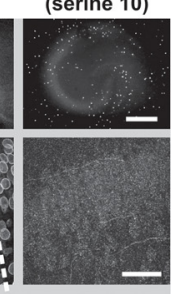

$\operatorname{lamin} \mathrm{A} / \mathrm{C}$

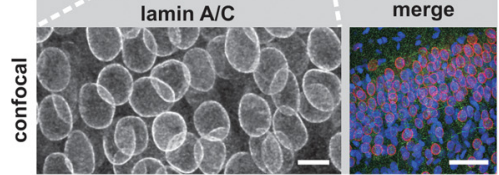

C
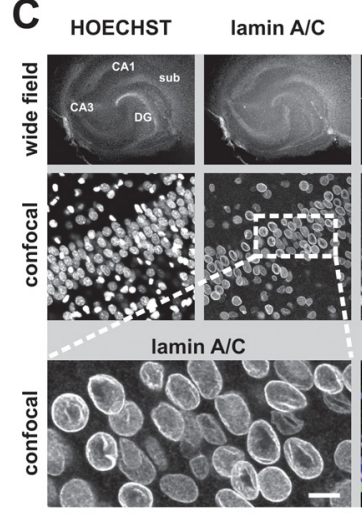

phospho H3 (serine 10)

D
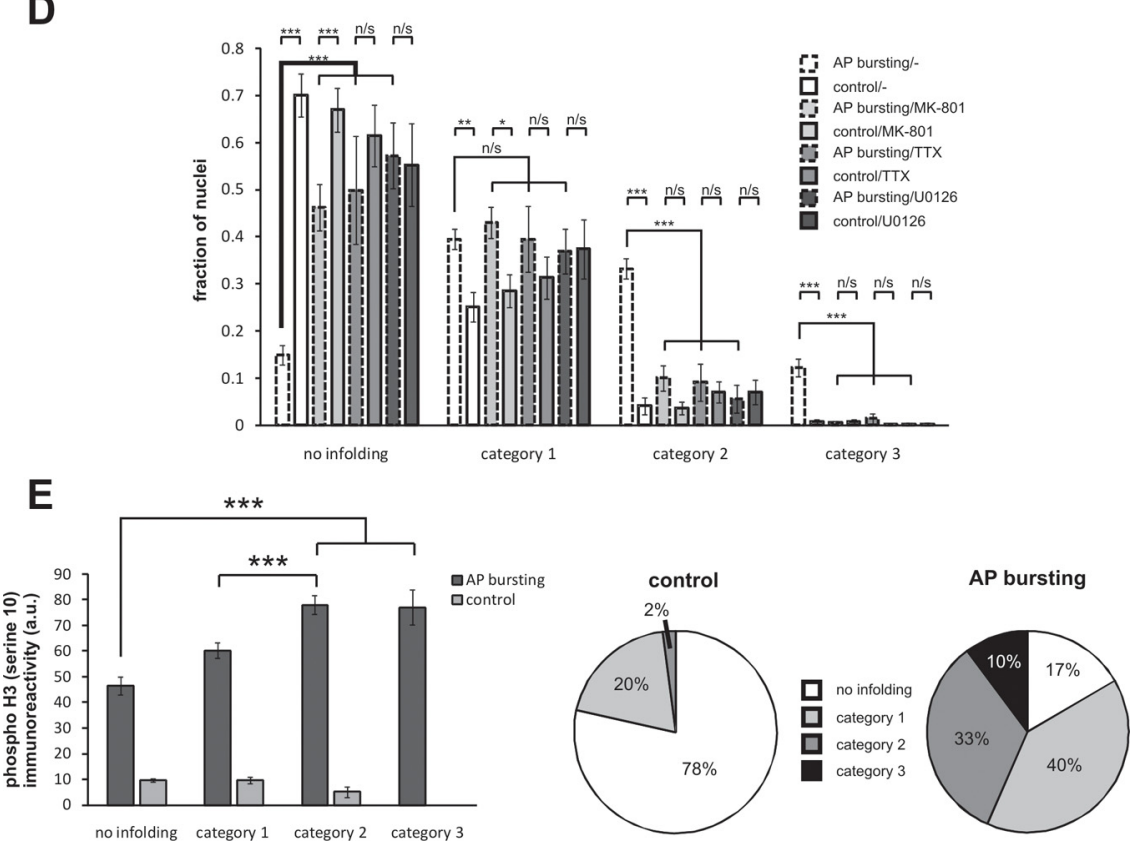

Figure 9. Action potential bursting induces nuclear infoldings and histone $\mathrm{H} 3$ phosphorylation at serine 10 in the pyramidal cell layer of hippocampal organotypic slice cultures (OTCS). A, Calcium imaging with Oregon Green 488 BAPTA-1 (OGB-1) in area CA1 of an OTC before and after bicuculline $(50 \mu \mathrm{m})$ treatment. Representative differential interference contrast (DIC) and fluorescence (OGB-1) images of CA1 are shown on the left panels (strat. or. = stratum oriens, strat. pyr. = stratum pyramidale, strat. rad. = stratum radiatum). Calcium signals shown on the right panels were measured in the stratum pyramidale. The gray lines represent individual traces of calcium transients measured in 30 randomly selected cells; the average calcium signals of all 30 cells are shown as black lines. The arrows indicate the time points of bicuculline application. $\boldsymbol{B}, \boldsymbol{C}$, Immunostaining of a vehicle-treated OTC (B) and an 0TC treated for $1 \mathrm{~h}$ with bicuculline (C) using lamin A/C antibodies and antibodies specific for the serine 10-phosphorylated form of histone H3. Representative images are shown. Top, Wide field images. The bright speckles in the phospho-histone H3 section represent nuclei of superficial cells (i.e., glial cells), which were undergoing cell division at the time of the experiment. Scale bar, $500 \mu \mathrm{m}$. Middle panels, High-resolution confocal images of the area CA1 of the 0TCs shown in the top. Bottom, High-magnification images of lamin A/C stainings (left; scale bar, $10 \mu \mathrm{m}$ ) and merged image of all three signals (right; scale bar, $50 \mu \mathrm{m}$ ). $D$, Quantitative analysis of nuclear infoldings in 0TCs. Vehicle-exposed (control) and stimulated ( $1 \mathrm{~h} \mathrm{AP} \mathrm{bursting} \mathrm{induced} \mathrm{by} 50 \mu \mathrm{N}$ bicuculline) 0TCs treated as indicated with MK-801 $(20 \mu \mathrm{M}), \mathrm{TTX}(1 \mu \mathrm{M})$, or U0126 $(10 \mu \mathrm{M})$ were fixed and processed for lamin A/C immunostaining. Nuclei of pyramidal neurons from the CA1 region of OTCs were categorized based on the lamin $\mathrm{A} / \mathrm{C}$ immunostaining and according to the criteria described in the legend of Figure 8C. Statistical analysis (ANOVA followed by Tukey's post hoc test) was done on bicuculline-treated vs control 0TCs within each inhibitor-treated group and between different inhibitor-treated
$12 \% \pm 1.9 \%$ (category 3 ) after bicuculline treatment (Fig. 9D). The increase in nuclear infoldings during burst activity was inhibited by MK-801 and UO126; in particular the fractions of nuclei that were in categories 2 and 3 after bicuculline treatment were virtually eliminated by the blockade of NMDA receptors and the ERK-MAP kinase signaling pathway (Fig. 9D). The activity-induced changes in nuclear geometry were paralleled by a robust induction of histone $\mathrm{H} 3$ phosphorylation on serine 10 with the strongest phospho-H3 immunoreactivity following bicuculline treatment being observed in infolded nuclei of the categories 2 and 3 (Fig. 9E). Thus, similar to the result obtained using dissociated hippocampal cultures, the nuclei of synaptically activated CA1 pyramidal neurons in a hippocampal slice preparation can undergo dramatic structural changes. The correlation between the formation of infoldings and the phosphorylation of histone $\mathrm{H} 3$ suggest a functional link between nuclear geometry and transcriptional regulation.

\section{Discussion}

Structural plasticity of the cell nucleus The development of a method for 3D image reconstruction of cell organelles from confocal microscopy data revealed a novel and rather surprising feature of NMDA receptor signaling in neurons. Neuronal nuclei are extremely plastic and their geometry is controlled by synaptic activity and NMDA receptor activation, with synaptically and extrasynaptically localized NMDA receptors having antagonistic effects. Activation of extrasynaptic NMDA signaling pathways that direct neurons toward degeneration and cell death (Hardingham et al., 2002) led to a loss of nuclear infoldings. In contrast, synaptic activity and calcium entry through synaptic NMDA receptors promoted the formation of infoldings. Given that chromosomes are not randomly arranged within the nucleus but organized in distinct

groups within the bicuculline-treated group and was indicated with asterisks $\left({ }^{* * *} p<0.001 ;{ }^{* *} p<0.005 ;{ }^{*} p<0.05 ; n / s\right.$, not significant). Error bars indicate SEM. E, Analysis of histone H3 phosphorylation in nuclei of different infolding categories. Intensities of the mean histone H3-phosphorylation signal averaged from 399 vehicle-treated (control) and 458 bicucullinetreated (AP bursting) neurons from OTCs are plotted with respect to their degree of infoldings. Pie charts indicate relative fractions of the four infoldings categories analyzed. Statistically significant differences (ANOVA followed by Tukey's post hoc test) are indicated with asterisks $\left({ }^{* * *} p<0.001\right)$. Error bars indicate SEM. 
chromosome territories (Cremer and Cremer, 2001), the dramatic changes in the nuclear architecture following stimulation of synaptic and extrasynaptic NMDA receptors may cause a spatial reorganization of chromosome territories. This could alter chromatin structures and accessibility and may affect gene transcription as well as other nuclear functions including pre-mRNA splicing and DNA repair.

\section{ERK-MAP kinase pathway and nuclear geometry}

Although the precise mechanisms through which the activation of synaptic or extrasynaptic NMDA receptors is translated into structural alterations of the cell nucleus remains to be investigated, the ERK-MAP kinase pathway appears to play a crucial role in the formation of new infoldings during synaptic activity. ERK-MAP kinases are part of a multifunctional signaling module that has been implicated in many aspects of neuronal physiology (Grewal et al., 1999; Sweatt, 2004). Their newly discovered and unexpected role in the translation of electrical events into changes in nuclear geometry raises the possibility that at least some of the numerous effects of blocking the ERK-MAP kinase signaling pathway on neuronal functions are the consequence of the blockade of signal-induced formation of nuclear infoldings.

Is there a 'nucleoplasmic reticulum' in hippocampal neurons? Our study answered a longstanding question about the existence of a nuclear calcium store. Intranuclear extensions of the ER have been described previously in several cell types and species (Echevarría et al., 2003). The ER is a massive calcium store and an ER extending into the nucleus could operate as an intranuclear calcium reservoir. Provided that calcium release channels reside on the inner nuclear envelope [as has been suggested previously (Mak and Foskett, 1994; Gerasimenko et al., 1995; Humbert et al., 1996; Santella and Kyozuka, 1997; Marchenko et al., 2005)], such a calcium store could release calcium directly into the nucleus thereby bypassing the cytosol. Our 3D reconstruction and EM results show that the invaginations are lined by both the inner and the outer nuclear envelope; this demonstrates that the invaginated space is filled with cytosol (and not ER lumen) and thus a nucleoplasmic reticulum does not exist in hippocampal neurons. Nevertheless, infoldings enhance nuclear calcium signaling not only because of the larger nuclear surface and the possible increased number of NPCs, which facilitates calcium flux into and out of the nucleus but also because diffusion distances from cytosolic to nuclear locations are smaller. Moreover, in highly infolded nuclei, compartmentalization occurs allowing microdomains and nuclear substructures to be formed that regulate calcium dynamics differently from other parts of the nucleus.

\section{Nuclear geometry, calcium signaling, and gene expression}

The compartments formed are often unequal in size with small nuclear compartments being better than large compartments in resolving a $5 \mathrm{~Hz}$ calcium signal originating in the soma. The increased resolution of high-frequency calcium oscillations in small compartments may be relevant for signal transmission and efficient activation of target molecules. There are indeed examples for individual molecules or cellular processes such as transcription being activated by calcium oscillations in a frequency-dependent manner. In the case of $\alpha \mathrm{CaM}$ kinase II, pulses of calcium signals at $4 \mathrm{~Hz}$ produce a more rapid and complete autophosphorylation of $\alpha \mathrm{CaM}$ kinase II than pulses at $1 \mathrm{~Hz}$ (De Koninck and Schulman, 1998). Moreover, in a Jurkat T cell line, particular calcium oscillations can enhance the signaling efficiency leading to the activation of gene expression (Dolmetsch et al., 1997). It remains to be investigated whether neuronal nuclei contain calcium-regulated molecules capable of decoding calcium oscillations in particular in the theta frequency range (i.e., $4-8 \mathrm{~Hz}$ ), which can be better resolved by the small than the large nuclear compartments.

Another feature of infolded nuclei that could impact on transcriptional regulation is the-compared with near-spherical nuclei-apparent increase in surface area and NPC immunoreactivity. There is very good evidence suggesting that actively transcribed DNA segments are located near NPCs (Taddei et al., 2006; Akhtar and Gasser, 2007). A possible increase in the number of NPCs in infolded nuclei may enhance the capacity of the nucleus for transcription-coupled anchoring of promoter regions to NPCs. This together with the phosphorylation of histones on serine 10 that preferentially takes place in highly infolded nuclei, may provide a significant advantage for neurons with infolded nuclei (over neurons with near-spherical nuclei) in optimizing steadystate gene expression and executing signal-induced transcriptional responses. Given that synaptically activated neurons form nuclear infoldings, this form of structural plasticity may present an adaptation to a metabolically more active state with an increased demand for gene expression.

\section{References}

Akhtar A, Gasser SM (2007) The nuclear envelope and transcriptional control. Nat Rev Genet 8:507-517.

al-Mohanna FA, Caddy KW, Bolsover SR (1994) The nucleus is insulated from large cytosolic calcium ion changes. Nature 367:745-750.

Arnold FJ, Hofmann F, Bengtson CP, Wittmann M, Vanhoutte P, Bading H (2005) Microelectrode array recordings of cultured hippocampal networks reveal a simple model for transcription and protein synthesisdependent plasticity. J Physiol 564:3-19.

Augustine GJ, Neher E (1992) Neuronal Ca2+ signalling takes the local route. Curr Opin Neurobiol 2:302-307.

Bading H (2000) Transcription-dependent neuronal plasticity: the nuclear calcium hypothesis. Eur J Biochem 267:5280-5283.

Bading H, Greenberg ME (1991) Stimulation of protein tyrosine phosphorylation by NMDA receptor activation. Science 253:912-914.

Bading H, Ginty DD, Greenberg ME (1993) Regulation of gene expression in hippocampal neurons by distinct calcium signaling pathways. Science 260:181-186.

Bading H, Segal MM, Sucher NJ, Dudek H, Lipton SA, Greenberg ME (1995) $N$-methyl-D-aspartate receptors are critical for mediating the effects of glutamate on intracellular calcium concentration and immediate early gene expression in cultured hippocampal neurons. Neuroscience 64:653-664.

Badminton MN, Campbell AK, Rembold CM (1996) Differential regulation of nuclear and cytosolic $\mathrm{Ca} 2+$ in HeLa cells. J Biol Chem 271:31210-31214.

Bastian P, Johannsen K, Lang S, Nägele S, Reichenberger V, Wieners C, Wittum G, Wrobel C (2000) Parallel solution of partial differential equations with adaptive multigrid methods on unstructured grids. In: High performance computing in science and engineering, pp 506-519. (Jäger W, Krause E, eds), New York: Springer.

Bengtson CP, Dick O, Bading H (2008) A quantitative method to assess extrasynaptic NMDA receptor function in the protective effect of synaptic activity against neurotoxicity BMC Neurosci 9:11.

Borsello T, Mottier V, Castagné V, Clarke PG (2002) Ultrastructure of retinal ganglion cell death after axotomy in chick embryos. J Comp Neurol 453:361-371.

Brami-Cherrier K, Valjent E, Hervé D, Darragh J, Corvol JC, Pages C, Arthur SJ, Simon AJ, Girault JA, Caboche J (2005) Parsing molecular and behavioral effects of cocaine in mitogen- and stress-activated protein kinase-1-deficient mice. J Neurosci 25:11444-11454.

Brami-Cherrier K, Lavaur J, Pagès C, Arthur JS, Caboche J (2007) Glutamate induces histone $\mathrm{H} 3$ phosphorylation but not acetylation in striatal neurons: role of mitogen- and stress-activated kinase-1. J Neurochem 101:697-708. 
Broser PJ, Schulte R, Lang S, Roth A, Helmchen F, Waters J, Sakmann B, Wittum G (2004) Nonlinear anisotropic diffusion filtering of threedimensional image data from two-photon microscopy. J Biomed Opt 9:1253-1264.

Chandramohan Y, Droste SK, Arthur JS, Reul JM (2008) The forced swimming-induced behavioural immobility response involves histone $\mathrm{H} 3$ phospho-acetylation and c-Fos induction in dentate gyrus granule neurons via activation of the $N$-methyl-D-aspartate/extracellular signalregulated kinase/mitogen- and stress-activated kinase signalling pathway. Eur J Neurosci 27:2701-2713.

Chawla S, Hardingham GE, Quinn DR, Bading H (1998) CBP: a signalregulated transcriptional coactivator controlled by nuclear calcium and CaM kinase IV. Science 281:1505-1509.

Chwang WB, Arthur JS, Schumacher A, Sweatt JD (2007) The nuclear kinase mitogen- and stress-activated protein kinase 1 regulates hippocampal chromatin remodeling in memory formation. J Neurosci 27:1273212742.

Collings DA, Carter CN, Rink JC, Scott AC, Wyatt SE, Allen NS (2000) Plant nuclei can contain extensive grooves and invaginations. Plant Cell 12:2425-2440.

Cremer T, Cremer C (2001) Chromosome territories, nuclear architecture and gene regulation in mammalian cells. Nat Rev Genet 2:292-301.

Daigle N, Beaudouin J, Hartnell L, Imreh G, Hallberg E, Lippincott-Schwartz J, Ellenberg J (2001) Nuclear pore complexes form immobile networks and have a very low turnover in live mammalian cells. J Cell Biol 154:71-84.

De Koninck P, Schulman H (1998) Sensitivity of CaM kinase II to the frequency of Ca2 + oscillations. Science 279:227-230.

Deak M, Clifton AD, Lucocq LM, Alessi DR (1998) Mitogen- and stressactivated protein kinase-1 (MSK1) is directly activated by MAPK and SAPK2/p38, and may mediate activation of CREB. EMBO J 17:4426-4441.

Doetsch F, García-Verdugo JM, Alvarez-Buylla A (1997) Cellular composition and three-dimensional organization of the subventricular germinal zone in the adult mammalian brain. J Neurosci 17:5046-5061.

Dolmetsch RE, Lewis RS, Goodnow CC, Healy JI (1997) Differential activation of transcription factors induced by $\mathrm{Ca} 2+$ response amplitude and duration. Nature 386:855-858.

Dorsey DA, Mascó DH, Dikranian K, Hyrc K, Masciotra L, Faddis B, Soriano M, Gru AA, Goldberg MP, de Erausquin GA (2006) Ultrastructural characterization of alpha-amino-3-hydroxy-5-methyl-4-isoxazolepropionic acid-induced cell death in embryonic dopaminergic neurons. Apoptosis 11:535-544.

Echevarría W, Leite MF, Guerra MT, Zipfel WR, Nathanson MH (2003) Regulation of calcium signals in the nucleus by a nucleoplasmic reticulum. Nat Cell Biol 5:440-446.

Eder A, Bading H (2007) Calcium signals can freely cross the nuclear envelope in hippocampal neurons: somatic calcium increases generate nuclear calcium transients. BMC Neuroscience 8:57.

Eriksson M, Brown WT, Gordon LB, Glynn MW, Singer J, Scott L, Erdos MR, Robbins CM, Moses TY, Berglund P, Dutra A, Pak E, Durkin S, Csoka AB, Boehnke M, Glover TW, Collins FS (2003) Recurrent de novo point mutations in lamin A cause Hutchinson-Gilford progeria syndrome. Nature 423:293-298.

Fricker M, Hollinshead M, White N, Vaux D (1997) Interphase nuclei of many mammalian cell types contain deep, dynamic, tubular membranebound invaginations of the nuclear envelope. J Cell Biol 136:531-544.

Frotscher M, Kraft J, Zorn U (1988) Fine structure of identified neurons in the primate hippocampus: a combined Golgi/EM study in the baboon. J Comp Neurol 275:254-270.

Gerasimenko OV, Gerasimenko JV, Tepikin AV, Petersen OH (1995) ATPdependent accumulation and inositol trisphosphate- or cyclic ADP-ribosemediated release of $\mathrm{Ca} 2+$ from the nuclear envelope. Cell 80:439-444.

Goldman RD, Gruenbaum Y, Moir RD, Shumaker DK, Spann TP (2002) Nuclear lamins: building blocks of nuclear architecture. Genes Dev 16:533-547.

Goldman RD, Shumaker DK, Erdos MR, Eriksson M, Goldman AE, Gordon LB, Gruenbaum Y, Khuon S, Mendez M, Varga R, Collins FS (2004) Accumulation of mutant lamin A causes progressive changes in nuclear architecture in Hutchinson-Gilford progeria syndrome. Proc Natl Acad Sci U S A 101:8963-8968.

Grewal SS, York RD, Stork PJ (1999) Extracellular-signal-regulated kinase signalling in neurons. Curr Opin Neurobiol 9:544-553.
Grynkiewicz G, Poenie M, Tsien RY (1985) A new generation of Ca2+ indicators with greatly improved fluorescence properties. J Biol Chem 260:3440-3450.

Hagenston AM, Fitzpatrick JS, Yeckel MF (2008) MGluR-mediated calcium waves that invade the soma regulate firing in layer $\mathrm{V}$ medial prefrontal cortical pyramidal neurons. Cereb Cortex 18:407-423.

Haithcock E, Dayani Y, Neufeld E, Zahand AJ, Feinstein N, Mattout A, Gruenbaum Y, Liu J (2005) Age-related changes of nuclear architecture in Caenorhabditis elegans. Proc Natl Acad Sci U S A 102:16690-16695.

Hardingham GE, Bading H (2003) The Yin and Yang of NMDA receptor signalling. Trends Neurosci 26:81-89.

Hardingham GE, Chawla S, Johnson CM, Bading H (1997) Distinct functions of nuclear and cytoplasmic calcium in the control of gene expression. Nature 385:260-265.

Hardingham GE, Arnold FJ, Bading H (2001a) Nuclear calcium signaling controls CREB-mediated gene expression triggered by synaptic activity. Nat Neurosci 4:261-267.

Hardingham GE, Arnold FJ, Bading H (2001b) A calcium microdomain near NMDA receptors: on switch for ERK-dependent synapse-to-nucleus communication. Nat Neurosci 4:565-566.

Hardingham GE, Fukunaga Y, Bading H (2002) Extrasynaptic NMDARs oppose synaptic NMDARs by triggering CREB shut-off and cell death pathways. Nat Neurosci 5:405-414.

Hayashi Y, Majewska AK (2005) Dendritic spine geometry: functional implication and regulation. Neuron 46:529-532.

Helmchen F (2002) Raising the speed limit-fast $\mathrm{Ca}(2+)$ handling in dendritic spines. Trends Neurosci 25:438-441.

Honavar M, Lantos PL (1987) Ultrastructural changes in the frontal cortex and hippocampus in the ageing marmoset. Mech Ageing Dev 41:161-175.

Humbert JP, Matter N, Artault JC, Köppler P, Malviya AN (1996) Inositol $1,4,5$-trisphosphate receptor is located to the inner nuclear membrane vindicating regulation of nuclear calcium signaling by inositol 1,4,5trisphosphate. Discrete distribution of inositol phosphate receptors to inner and outer nuclear membranes. J Biol Chem 271:478-485.

Johenning FW, Holthoff K (2007) Nuclear calcium signals during L-LTP induction do not predict the degree of synaptic potentiation. Cell Calcium 41:271-283.

Lafarga M, Berciano MT, Martinez-Guijarro FJ, Andres MA, Mellström B, Lopez-Garcia C, Naranjo JR (1992) Fos-like expression and nuclear size in osmotically stimulated supraoptic nucleus neurons. Neuroscience 50:867-875.

Lee B, Butcher GQ, Hoyt KR, Impey S, Obrietan K (2005) Activitydependent neuroprotection and cAMP response element-binding protein (CREB): kinase coupling, stimulus intensity, and temporal regulation of CREB phosphorylation at serine 133. J Neurosci 25:1137-1148.

Lim RY, Fahrenkrog B (2006) The nuclear pore complex up close. Curr Opin Cell Biol 18:342-347.

Limbäck-Stokin K, Korzus E, Nagaoka-Yasuda R, Mayford M (2004) Nuclear calcium/calmodulin regulates memory consolidation. J Neurosci 24:10858-10867.

Lonze BE, Ginty DD (2002) Function and regulation of CREB family transcription factors in the nervous system. Neuron 35:605-623.

Mak DO, Foskett JK (1994) Single-channel inositol 1,4,5-trisphosphate receptor currents revealed by patch clamp of isolated Xenopus oocyte nuclei. J Biol Chem 269:29375-29378.

Marchenko SM, Yarotskyy VV, Kovalenko TN, Kostyuk PG, Thomas RC (2005) Spontaneously active and InsP3-activated ion channels in cell nuclei from rat cerebellar Purkinje and granule neurones. J Physiol 565:897-910.

Meyers J, Craig J, Odde DJ (2006) Potential for control of signaling pathways via cell size and shape. Curr Biol 16:1685-1693.

Milner B, Squire LR, Kandel ER (1998) Cognitive neuroscience and the study of memory. Neuron 20:445-468.

Mounkes LC, Kozlov S, Hernandez L, Sullivan T, Stewart CL (2003) A progeroid syndrome in mice is caused by defects in A-type lamins. Nature 423:298-301.

Muller D, Nikonenko I, Jourdain P, Alberi S (2002) LTP, memory and structural plasticity. Curr Mol Med 2:605-611.

Nakazawa H, Murphy TH (1999) Activation of nuclear calcium dynamics by synaptic stimulation in cultured cortical neurons. J Neurochem 73:1075-1083.

O'Malley DM (1994) Calcium permeability of the neuronal nuclear enve- 
lope: evaluation using confocal volumes and intracellular perfusion. J Neurosci 14:5741-5758.

Olins AL, Buendia B, Herrmann H, Lichter P, Olins DE (1998) Retinoic acid induction of nuclear envelope-limited chromatin sheets in HL-60. Exp Cell Res 245:91-104.

Otsu N (1979) Threshold selection method from gray-level histograms. IEEE Trans Sys Man Cyber 19:62-66.

Papadia S, Stevenson P, Hardingham NR, Bading H, Hardingham GE (2005) Nuclear $\mathrm{Ca} 2+$ and the cAMP response element-binding protein family mediate a late phase of activity-dependent neuroprotection. J Neurosci 25:4279-4287.

Power JM, Sah P (2002) Nuclear calcium signaling evoked by cholinergic stimulation in hippocampal CA1 pyramidal neurons. J Neurosci 22: $3454-3462$.

Queisser G, Wittmann M, Bading H, Wittum G (2008) Filtering, reconstruction and measurement of the geometry of nuclei from hippocampal neurons based on confocal microscopy data. J Biomed Optics 13:014009.

Raymond CR, Redman SJ (2006) Spatial segregation of neuronal calcium signals encodes different forms of LTP in rat hippocampus. J Physiol 570:97-111.

Regehr WG, Tank DW (1994) Dendritic calcium dynamics. Curr Opin Neurobiol 4:373-382.

Ribak CE, Seress L (1983) Five types of basket cell in the hippocampal dentate gyrus: a combined Golgi and electron microscopic study. J Neurocytol 12:577-597.

Santella L, Kyozuka K (1997) Effects of 1-methyladenine on nuclear Ca2 + transients and meiosis resumption in starfish oocytes are mimicked by the nuclear injection of inositol 1,4,5-trisphosphate and cADP-ribose. Cell Calcium 22:11-20.

Scaffidi P, Misteli T (2006) Lamin A-dependent nuclear defects in human aging. Science 312:1059-1063.

Seri B, Herrera DG, Gritti A, Ferron S, Collado L, Vescovi A, Garcia-Verdugo
JM, Alvarez-Buylla A (2006) Composition and organization of the SCZ: a large germinal layer containing neural stem cells in the adult mammalian brain. Cereb Cortex 16 (Suppl 1):i103-i111.

Soloaga A, Thomson S, Wiggin GR, Rampersaud N, Dyson MH, Hazzalin CA, Mahadevan LC, Arthur JS (2003) MSK2 and MSK1 mediate the mitogen- and stress-induced phosphorylation of histone H3 and HMG14. EMBO J 22:2788-2797.

Soriano E, Nitsch R, Frotscher M (1990) Axo-axonic chandelier cells in the rat fascia dentata: Golgi-electron microscopy and immunocytochemical studies. J Comp Neurol 293:1-25.

Stoppini L, Buchs PA, Muller D (1991) A simple method for organotypic cultures of nervous tissue. J Neurosci Methods 37:173-182.

Sweatt JD (2004) Mitogen-activated protein kinases in synaptic plasticity and memory. Curr Opin Neurobiol 14:311-317.

Tada T, Sheng M (2006) Molecular mechanisms of dendritic spine morphogenesis. Curr Opin Neurobiol 16:95-101.

Taddei A, Van Houwe G, Hediger F, Kalck V, Cubizolles F, Schober H, Gasser SM (2006) Nuclear pore association confers optimal expression levels for an inducible yeast gene. Nature 441:774-778.

Van Aelst L, Cline HT (2004) Rho GTPases and activity-dependent dendrite development. Curr Opin Neurobiol 14:297-304.

Watanabe S, Hong M, Lasser-Ross N, Ross WN (2006) Modulation of calcium wave propagation in the dendrites and to the soma of rat hippocampal pyramidal neurons. J Physiol 575:455-468.

West AE, Griffith EC, Greenberg ME (2002) Regulation of transcription factors by neuronal activity. Nat Rev Neurosci 3:921-931.

Wiegert JS, Bengtson CP, Bading H (2007) Diffusion and not active transport underlies and limits ERK1/2 synapse-to-nucleus signaling in hippocampal neurons. J Biol Chem 282:29621-29633.

Yuste R, Majewska A, Holthoff K (2000) From form to function: calcium compartmentalization in dendritic spines. Nat Neurosci 3:653-659. 